\title{
Autism Spectrum Disorder and Clinical High Risk for Psychosis: A Systematic Review and Meta-analysis
}

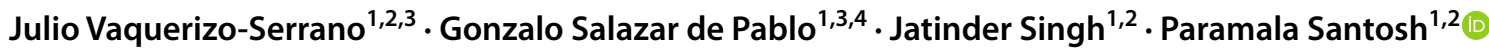

Accepted: 25 April 2021 / Published online: 15 May 2021

(c) The Author(s) 2021

\begin{abstract}
Psychotic experiences can occur in autism spectrum disorders (ASD). Some of the ASD individuals with these experiences may fulfil Clinical High-Risk for Psychosis (CHR-P) criteria. A systematic literature search was performed to review the information on ASD and CHR-P. A meta-analysis of the proportion of CHR-P in ASD was conducted. The systematic review included 13 studies. The mean age of ASD individuals across the included studies was 11.09 years. The Attenuated Psychosis Syndrome subgroup was the most frequently reported. Four studies were meta-analysed, showing that $11.6 \%$ of CHR-P individuals have an ASD diagnosis. Symptoms of prodromal psychosis may be present in individuals with ASD. The transition from CHR-P to psychosis is not affected by ASD.
\end{abstract}

Keywords Autism spectrum disorders · Clinical high-risk for psychosis $\cdot$ Psychosis $\cdot$ Prodromal psychosis $\cdot$ Systematic review $\cdot$ Meta-analysis

Autism spectrum disorders (ASD) are early-onset neurodevelopmental disorders categorised by persistent deficits in social communication and restricted and repetitive patterns of behaviour (American Psychiatric Association, 2013). ASD and psychotic disorders have symptomatic overlap and were historically considered related conditions (Kanner, 1965; Ornitz \& Ritvo, 1968). Initially, ASD was viewed as

Paramala Santosh

paramala.1.santosh@kcl.ac.uk

1 Department of Child and Adolescent Psychiatry, Institute of Psychiatry, Psychology and Neuroscience, King's College London, 16 De Crespigny Park, London SE5 8AF, UK

2 Centre for Interventional Paediatric Psychopharmacology and Rare Diseases (CIPPRD), National and Specialist Child and Adolescent Mental Health Services, Maudsley Hospital, London, UK

3 Early Psychosis: Interventions and Clinical-Detection (EPIC) Lab, Department of Psychosis Studies, Institute of Psychiatry, Psychology and Neuroscience, King's College London, London, UK

4 Institute of Psychiatry and Mental Health, Department of Psychiatry, Hospital General Universitario Gregorio Marañón Instituto de Investigación Sanitaria Gregorio Maranón, Universidad Complutense, Centro de Investigación Biomédica en Red Salud Mental (CIBERSAM), Madrid, Spain an early manifestation of psychosis (Bleuler, 1911; Kanner, 1943); nevertheless, autism and psychosis have been categorised as separate conditions (Kolvin, 1971) from the third edition of the Diagnostic and Statistical Manual of Mental Disorders, (DSM-III) (American Psychiatric Association, 1987), onwards.

ASD and psychotic disorders represent disabling neurodevelopmental conditions with marked deficiencies in social functioning, which may coexist more frequently than would be expected by chance (Davidson et al., 2014; Selten et al., 2015). Both conditions are highly heterogeneous, involving many complex features (Crespi \& Badcock, 2008), and have been found to share several risk factors (Chisholm et al., 2015).

Increased paternal age (Hamlyn et al., 2013); obstetric complications (Hamlyn et al., 2013); specific genetic pathways (Burbach \& van der Zwaag, 2009; Kushima et al., 2018); abnormalities in brain development (Toal et al., 2009); neuroanatomical markers (Toal et al., 2009), and social cognition deficits (Sugranyes et al., 2011a) are risk factors for ASD and psychosis. Additionally, a recent metaanalysis found that a diagnosis of ASD is a risk factor for developing psychosis (Lai et al., 2019; Zheng et al., 2018), with individuals with ASD being 3.5 times more likely to develop psychosis than the general population (Zheng et al., 2018). 
Disorders on the autism spectrum and psychotic disorders might be considered as two extremes of the ASD-Psychosis continuum based on social cognition (Crespi \& Badcock, 2008), and regulated by alterations in genomic imprinting (Badcock \& Crespi, 2006), anatomical structure, as well as the function of the interacting amygdala, hippocampus, and prefrontal cortical circuitry (Baron-Cohen \& Belmonte, 2005; Burns, 2004, 2006; Gisabella et al., 2005). With regards to neuroanatomical markers, and considering brain size, the existing evidence suggests that the amygdala and hippocampus is larger in ASD during early development compared to controls (Schumann et al., 2004), although this pattern is largely gone by adolescence and adulthood (Cheung et al., 2010; Courchesne et al., 2007). Further, there is evidence that indicates overgrowth of the brain in very young children at high risk of psychosis (Gilmore et al., 2010). Conversely, the brain is smaller in psychotic disorders during adulthood (Aleman \& Kahn, 2005; Geuze et al., 2005; Gur et al., 2007; Kuroki et al., 2006).

ASD and psychotic disorders are considered to be influenced by dysregulated development of the social brain (AbuAkel et al., 2015; Broks, 1997; Burns, 2006; Emery, 2000; Pourcain et al., 2018; Ziermans et al., 2020). It has been suggested that ASD and psychosis represent extremes on a continuum of human cognitive architecture from mentalistic cognition, (for example, theory of mind), to mechanistic cognition, (i.e. interaction with the physical environment) (Badcock, 2004; Crespi \& Badcock, 2008). This model suggests that ASD and psychotic disorders represent opposite extremes of a social cognition continuum (Abu-Akel, \& Bailey, 2000; Crespi \& Badcock, 2008), in which ASD is associated with under-active mechanistic social cognition, and psychotic disorders with hyper-active mentalistic social cognition, diverging in opposite directions from typical performance (Abu-Akel, \& Bailey, 2000; Abu-Akel et al., 2015). In terms of social cognition, it is known that social cognition is altered in ASD, especially in social personal interactions (Baron-Cohen \& Belmonte, 2005; BishopFitzpatrick et al., 2017; Rosello et al., 2020), whereas in psychotic disorders, especially in schizophrenia spectrum disorders, the abnormality is different and focussed on paranoid interpretation (Harrington et al., 2005b). In this line, a specific link between paranoid delusions and a deterioration of the theory of the mind has been suggested (Harrington et al., 2005a).

There has been an increasing interest in the overlap of ASD and prodromal symptoms of psychosis (Chisholm et al., 2015; Sampson et al., 2020). The shared clinical features among both conditions include unusual thought content, deficits in social interaction, and stereotyped behaviours (De Crescenzo et al., 2019; Hommer \& Swedo, 2015). Furthermore, various studies have reported social cognitive deficits, a core symptom in ASD, in individuals at risk for psychosis (Lavoie et al., 2013; Lee et al., 2015). Several models have been suggested in computational neuroscience that helps to frame the basic brain-based mechanisms that might lead to the phenomenology of social cognitive dysfunction and the dimensions of the most common symptoms in individuals diagnosed with psychosis (Adams et al., 2013; Iglesias et al., 2017; Vladusich, 2008). Cognitive mechanisms proposed for psychotic symptoms, such as hallucinations, include a suggested abnormal perception resulting from an imbalance between (i) higher-order information processing, (i.e. perceptual expectations or previous knowledge), and (ii) lower-order perceptual processing of external sensory information (Aleman et al., 2003), and those experiences might be formed when higher-order cognition is prioritised over the lower-order sensory information (Hoffman et al., 2007; Hugdahl, 2009). Similarly, some symptoms present in ASD might result from an imbalance between top-down and bottom-up perceptual processing (Palmer et al., 2015; Van de Cruys et al., 2014). In this line, some psychotic symptoms might be explained in terms of a failure of top-down predictions (Adams et al., 2013). or an enhanced weighting of bottom-up prediction errors (Horga et al., 2014). Conversely, individuals with ASD are exceedingly influenced by a lower-order sensory information processing (Grossberg \& Seidman, 2006).

The Clinical High-Risk state for psychosis designation (hereinafter CHR-P), also known as the "At-Risk Mental State", (ARMS) (Schultze-Lutter et al., 2011), is defined as a status that confers high, but not inevitable risk, of developing psychosis, which implies that psychotic-like symptoms do not invariably lead to an acute psychotic episode (McGorry \& Singh, 1995; Yung et al., 1996), describing individuals presenting with potentially prodromal symptoms (Fusar-Poli et al., 2013a, b). In terms of conversion to psychosis, the proportion of individuals at CHR-P who develop a psychotic disorder has been reported to be $22 \%$ at 3 years in a recent meta-analysis (Fusar-Poli et al., 2020a).

The CHR-P includes the (i) Attenuated Psychosis Syndrome (APS), defined as the presence of sub-threshold positive psychotic symptoms for at least 1 month during the past year; (ii) Brief Limited Intermittent Psychotic Symptoms (BLIPS), which is an episode of frank psychotic symptoms that spontaneously end within a week, and (iii) Genetic Risk and Deterioration Syndrome (GRD), which requires a significant deterioration in functioning for at least 1 month within the last 12 months, and a family history of a firstdegree relative with a psychotic disorder or schizotypal personality disorder (Fusar-Poli et al., 2014a, 2016, 2020a, b; McGlashan et al., 2019; Salazar De Pablo et al., 2020) (eSupplementary Table 1).

Additionally, Basic Symptoms, considered as an immediate symptomatic expression of the neurobiological processes underlying psychosis, have been reported in individuals at 
CHR-P (Schultze-Lutter \& Theodoridou, 2017; SchultzeLutter et al., 2012). Basic Symptoms are defined as subtle subclinical disturbances in mental processes, such as affect, thinking, speech, perception, motor action and central-vegetative functions, with full insight into their abnormal nature (Schultze-Lutter \& Theodoridou, 2017; Schultze-Lutter et al., 2012) (eSupplementary Table 2).

To our knowledge, this is the first systematic review, complemented by meta-analytical evidence, that comprehensively assesses the association between ASD and CHR-P. The aims of this study were (i) to describe the relationship between ASD and CHR-P; (ii) to understand the distinctive and overlapping features of ASD and CHR-P, including clinical, cognitive and pharmacological aspects; (iii) to provide evidence of the presence of ASD in CHR-P, and (iv) to conduct a meta-analysis into the co-occurrence of ASD and CHR-P.

\section{Methods}

This study was conducted in accordance with the Preferred Reporting Items for Systematic Reviews and Meta-analyses (PRISMA) reporting guideline (Page et al., 2021), and the Meta-analysis of Observational Studies in Epidemiology (MOOSE) reporting guideline (Stroup et al., 2000) (eSupplementary Table 3 ). The study protocol was registered in PROSPERO (CRD42020183153).

\section{Search Strategy and Selection Criteria}

A multistep literature search was performed by two independent researchers (JVS and GSP) through Pubmed and Web of Science database (Clarivate Analytics), incorporating the Web of Science Core Collection, BIOSIS Citation Index, KCI-Korean Journal Database, MEDLINE, Russian Science Citation Index, SciELO Citation Index, Cochrane Central Register of Reviews and Ovid/PsychINFO databases from inception until 5th October 2020, using the following keywords: ("Risk" OR "Prodrom*" OR "Ultra-High Risk" OR "Clinical High Risk” OR "Attenuat*” OR "APS” OR "High Risk" OR "Brief Limited" OR "Brief Intermittent" OR “BLIPS” OR “Genetic High Risk” OR “GRD” OR “At Risk Mental State”" OR "Risk of Progression” OR "Progression to First-Episode” OR "Basic Symptoms”) AND ("Psychosis" OR "Schizophrenia" OR "Schizoaffective" OR "First Episode Psychosis" OR "FEP") AND ("Autism" OR “Autis*” OR “Autism Spectrum Disorders" OR "Autistic Disorder" OR "ASD” OR “Asperger Syndrome” $O R$ "Asperger" OR "Pervasive” OR "PDD” OR "Childhood Disintegrative Disorder” OR “CDD”).

We also searched the preprint servers medRxiv and PsyArXiv from inception until 5th October 2020, using the keywords "Autism" AND "Clinical High Risk" AND Psychosis". Additionally, the references of prior studies that were retrieved, were manually searched. Abstracts of articles identified that were not relevant were screened out. The remaining full-text articles were then assessed for inclusion eligibility against the inclusion and exclusion criteria.

\section{Eligibility Criteria}

\section{Inclusion Criteria}

Studies included were: (1) individual studies, including abstracts, conference proceedings or grey literature; (2) in (i) CHR-P individuals (i.e., individuals meeting clinical-highrisk, prodromal psychosis and/or basic symptoms criteria as established by validated psychometric instruments), in whom the presence of ASD is reported, (ii) individuals with ASD in whom the presence of CHR-P is reported, and (iii) in which the overlapping and distinctive features between ASD and CHR-P are described, providing relevant data on the relationship between both conditions; and (3) published in English (eSupplementary Methods 1-2).

For the meta-analysis, additional inclusion criteria were: (1) reporting meta-analysable data, and (2) non-overlapping samples. Overlap was actively searched in the included studies by looking at the country, setting, university and program from which the sample was obtained, as well as the recruitment period. When more than one study from the same sample was detected, the study with the largest sample was included.

\section{Exclusion Criteria}

The exclusion criteria used were: (1) reviews, clinical cases and study protocols; (2) studies that did not formally assess and select participants at CHR-P or with ASD, and (3) studies written in languages other than English.

\section{Outcome Measures and Data Extraction}

Data were independently extracted by two researchers (JVS and GSP), and discrepancies were resolved through consulting a third senior academic (PS). The variables extracted included: study (first author and year of publication); study design, (cross-sectional, longitudinal, clinical trials); setting (program or department); country; sample size; age (mean, SD); sex (\% males); assessment instruments; comorbidity (if applicable); treatment received, (if applicable); key findings, and quality assessment. 


\section{Quality Assessment}

Study quality was assessed in all in the included studies. Though quality assessments can be reliably conducted in meta-analyses of experimental research, their use in observational studies is controversial, with no clear consensus on rating methods or their appropriate use in the analysis (Jüni et al., 1999). A modified version of the Newcastle-Ottawa Scale which has been used in recent meta-analyses in the field (Fusar-Poli et al., 2015; Salazar De Pablo et al., 2020) was used for the evaluation of cross-sectional and longitudinal studies, (www.ohri.ca/programs/clinical_epidemiolo gy/oxford.asp). Scores ranged from 0 to 8 (eSupplementary Table 4).

\section{Data Synthesis and Meta-analysis}

We systematically reviewed the available evidence on the relationship between ASD and CHR-P, focusing on distinctive and overlapping features, including clinical, psychopathological, therapeutic, cognitive and neurobiological aspects. The primary outcome was the presence of ASD in CHR-P individuals, $(\%, \mathrm{SE})$. Because the studies in this metanalysis were expected to be heterogeneous, the random-effects model was used. (DerSimonian \& Laird, 1986 Heterogeneity among studies point estimates was assessed with the $\mathrm{Q}$ statistic. The magnitude of heterogeneity was evaluated with the I-squared index (Lipsey \& Wilson, 2001). Publication bias was examined by visually inspecting funnel plots (Sterne et al., 2001) and applying the regression intercept of Egger (Egger et al., 1997). Due to the limited number of studies available, we could not test moderating factors using meta-regression analysis to evaluate sources of heterogeneity, in line with previous meta-analyses, that perform these analyses when at last ten studies per outcome are available (Salazar De Pablo et al., 2020). All p-values reported in the meta-analysis were two-sided and the level of significance was set at a p-value of less than 0.05. We used Comprehensive Meta-analysis Software, version 3 (Biostat, Inc) (Borenstein et al., 2005).

\section{Results}

\section{Database}

The literature search yielded 1903 citations which were screened for eligibility. Of those, 1838 were excluded during the title and abstract screening, and 65 articles were assessed full text. This process resulted in a total of 13 studies being integrated into the current systematic review, which included a total of 16,474 individuals after removing duplicates. The data available allowed us to conduct quantitative meta-analyses of the proportion of CHR-P individuals fulfilling ASD criteria. After excluding overlapping samples and those studies that did not provide meta-analysable data, four studies were included in the meta-analysis on the prevalence of ASD in CHR-P (Foss-Feig et al., 2019; Maat et al., 2020; Solomon et al., 2011; Sprong et al., 2008) (Fig. 1 PRISMA Flowchart).

\section{Study Characteristics}

The characteristics of the included studies are presented in Table 1. Nine studies $(69.2 \%)$ were from the US (FossFeig et al., 2018, 2019; Guillory et al., 2018a, b; Jutla et al., 2020a, b; Solomon et al., 2008, 2011; Wilson et al., 2020), three (23.1\%) from Europe (Eussen et al., 2014; Maat et al., 2020; Sprong et al., 2008) and one (7.7\%) from Australasia (Fraser et al., 2008). All 13 studies reported on general characteristics of ASD and CHR-P state. Considering the measures to assess the CHR-P status, eight studies used the Structured Interview for Psychosis-Risk Syndromes (SIPS) (Foss-Feig et al., 2018, 2019; Guillory et al., 2018a, b; Maat et al., 2020; Solomon et al., 2011; Sprong et al., 2008; Wilson et al., 2020); four used the Scale of Prodromal Symptoms (SOPS) (Foss-Feig et al., 2018, 2019; Guillory et al., 2018a, b); one study the Comprehensive Assessment of At Risk Mental States (CAARMS) (Eussen et al., 2014); one used the Prodromal Questionnaire (PQ) (Eussen et al., 2014); two the Prodromal Questionnaire-Brief Child version (PQ-BC) (Jutla et al., 2020a, b); two the KiddieFormal Thought Disorder Rating Scale (KFTDS) (Eussen et al., 2014; Solomon et al., 2008), and one study the Bonn Scale for the Assessment of Basic Symptoms-Prediction List (BSABS-P) (Sprong et al., 2008).

The mean age of ASD individuals across the included studies was 11.09 years. Likewise, the mean age of CHR-P individuals within the included studies was 18.23 years. Seven (53.8\%) studies included only children and adolescents (Eussen et al., 2014; Jutla et al., 2020a, b; Maat et al., 2020; Solomon et al., 2008; Sprong et al., 2008; Wilson et al., 2020). Moreover, most of the included studies had a higher percentage of males (53.5\% of the total sample) (Summary Findings in Table 2).

At baseline, and considering the different CHR-P groups, (APS, BLIPS and GRD), the APS group was the most frequently reported in the CHR-P sample with ASD, reaching up to 100\% (Foss-Feig et al., 2019; Maat et al., 2020; Solomon et al., 2011). In addition, $4 \%$ met criteria for GRD (Foss-Feig et al., 2019) and 3.1\% fulfilled criteria for BLIPS (Sprong et al., 2008). Furthermore, 36.7\% ASD individuals met criteria for basic symptoms (Sprong et al., 2008). Among those CHR-P individuals without ASD, 91.3-100\% met the APS criteria (Foss-Feig et al., 2019; Maat et al., 2020; Solomon et al., 2011; Sprong et al., 2008), 4.6-11.3\% 
Fig. 1 PRISMA flow diagram

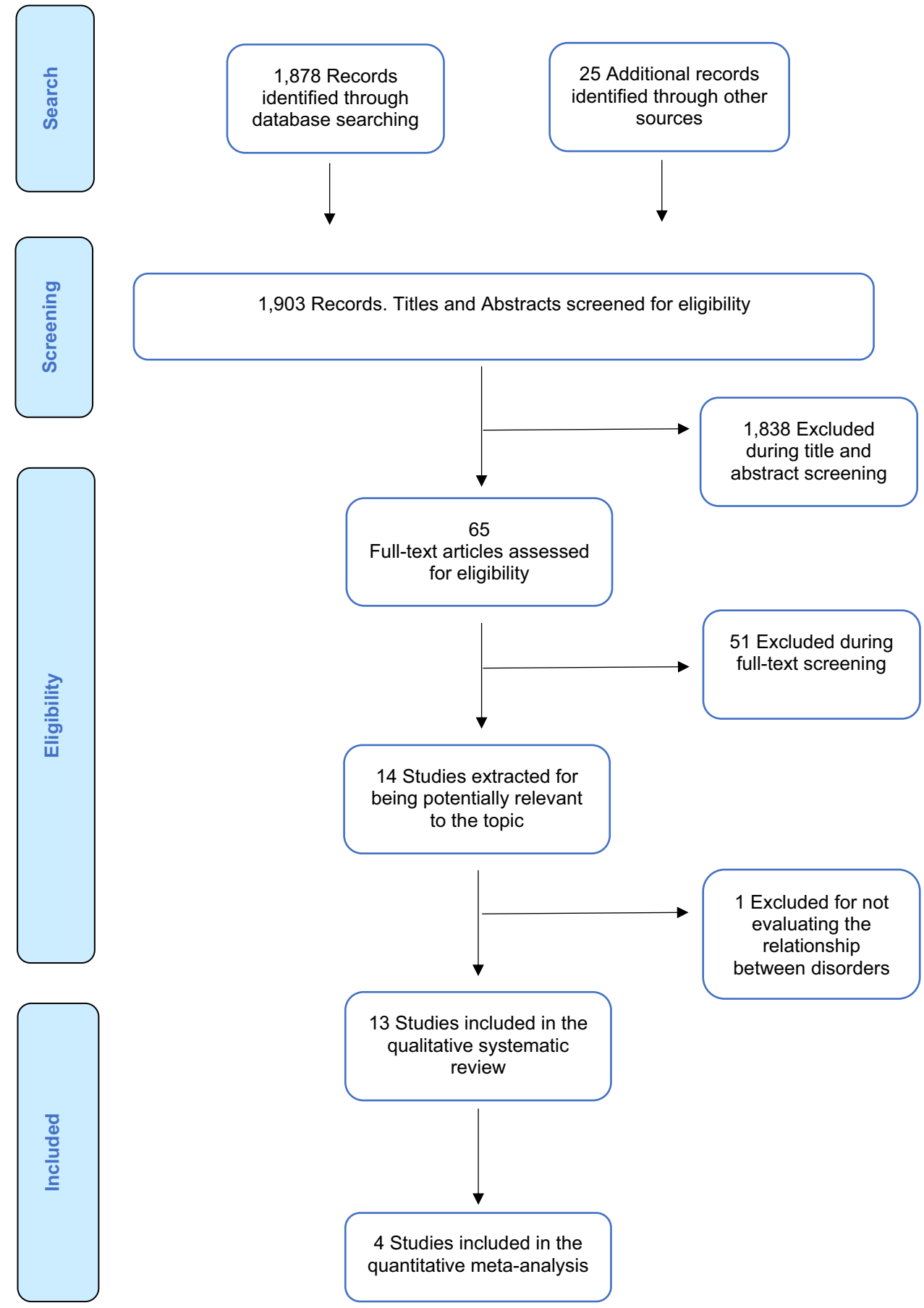

met GRD criteria (Foss-Feig et al., 2019; Maat et al., 2020; Sprong et al., 2008) and 0.8-11.3\% met BLIPS criteria (Foss-Feig et al., 2019; Maat et al., 2020; Sprong et al., 2008).

\section{Clinical Comorbidity}

Two studies also reported on the presence of other symptomatic domains in ASD (Eussen et al., 2014; Wilson et al.,
2020). Symptoms of anxiety were reported between 14.0 (Wilson et al., 2020) to 44.0\% (Eussen et al., 2014). In addition, between 33.0 (Eussen et al., 2014) and 52.0\% (Wilson et al., 2020) of those individuals with ASD met criteria for Attention Deficit Hyperactivity Disorder (ADHD). Further, 22.0\% were diagnosed with Oppositional Defiant Disorder (ODD), 8.8\% with Mood Disorder (Eussen et al., 2014) and 5.0\%. with Tourette's Disorder (Wilson et al., 2020). 


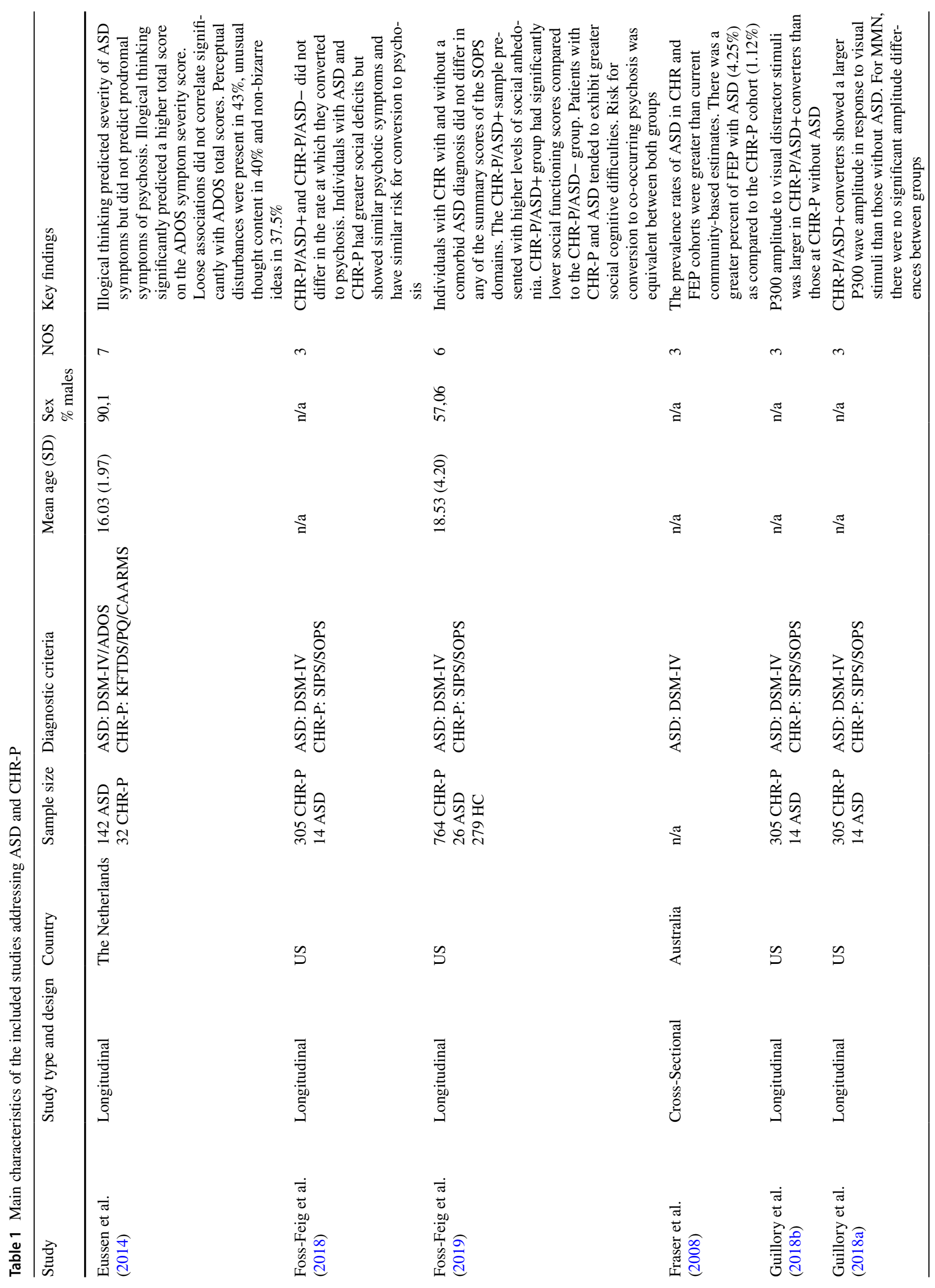




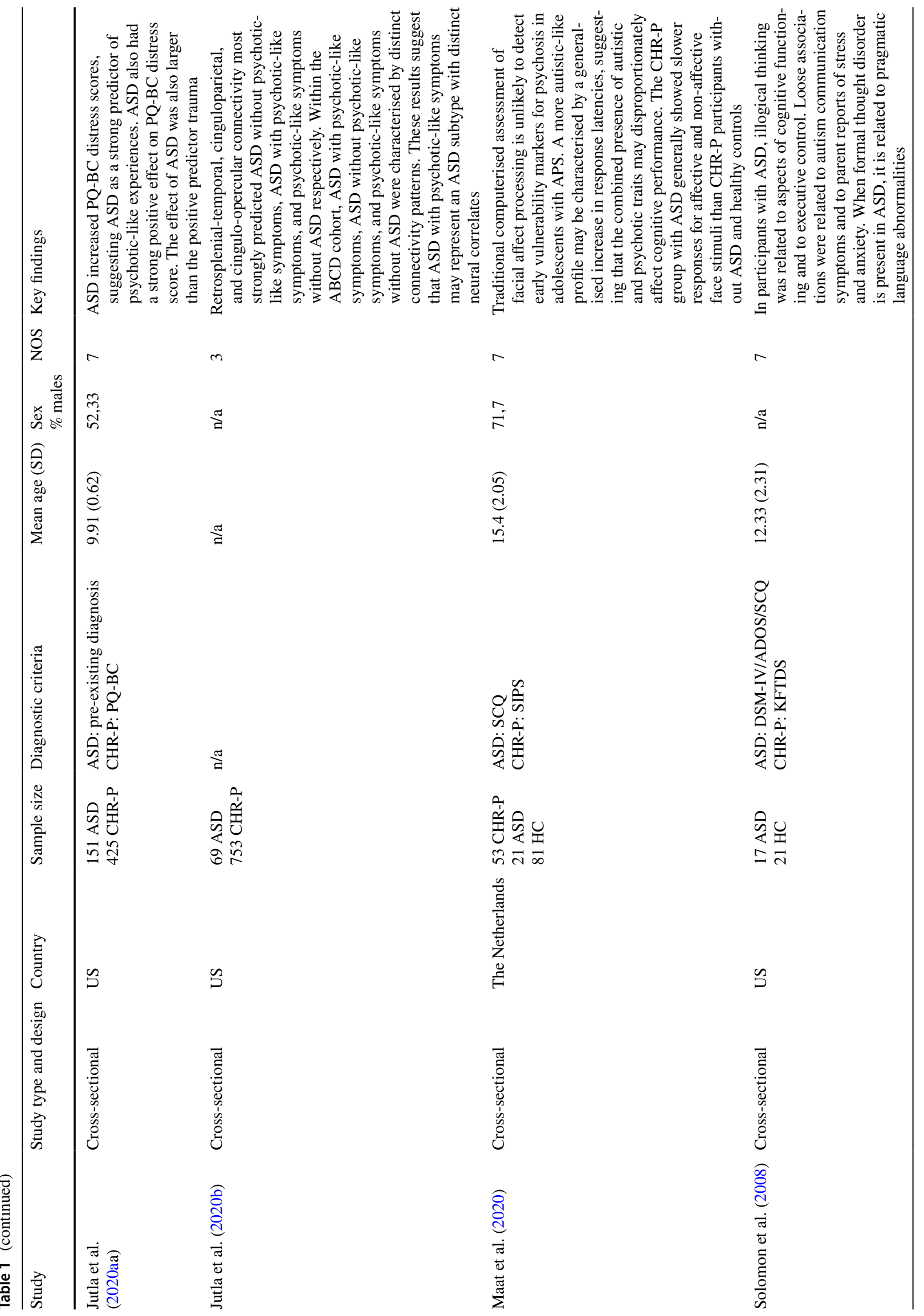




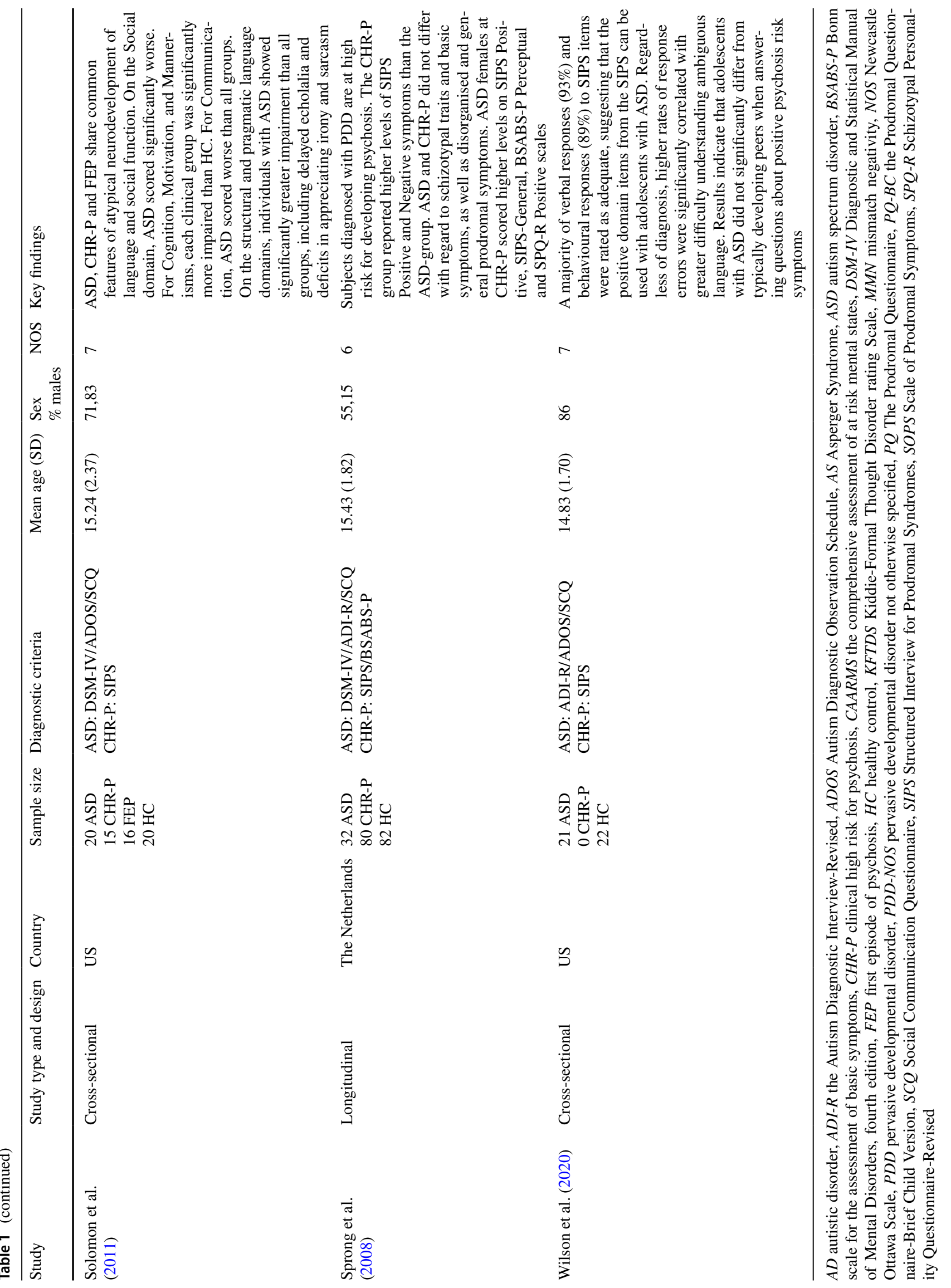


Table 2 Summary findings

\begin{tabular}{|c|c|c|}
\hline & Systematic review findings & Metaanalysis ASD-CHR-P \\
\hline SD \& CHR-P & $\begin{array}{l}\text { - Studies: } 13 \\
\text { - N=16,474 individuals } \\
\text { - Mean age range: } 8.82-18.53 \text { years } \\
\text { - Males: } 53.5 \% \\
\text { - The APS group was the most frequent reported: } 100 \% \text {. } \\
4 \% \text { met criteria for GRD and } 3.1 \% \text { met criteria for BLIPS. } \\
36.7 \% \text { met criteria for basic symptoms } \\
\text { - ADHD was present in } 33.0-52.0 \% \text {. Anxiety disorders in } \\
\text { 14.0-44.0\%. ODD in } 22.0 \% \text {. Mood disorders in } 8.8 \% \text {. Tou- } \\
\text { rette's disorder in 5.0\% } \\
\text { - ASD individuals at CHR-P showed significantly greater } \\
\text { impairment in structural and pragmatic language and social } \\
\text { functioning domains } \\
\text { - CHR-P with ASD had higher impairment in facial affect } \\
\text { recognition and showed slower responses for affective and } \\
\text { non-affective face stimuli than those without ASD } \\
\text { - ASD individuals at CHR-P had poorer social cognition } \\
\text { - ASD at CHR-P showed a larger P300 wave amplitude in } \\
\text { response to visual stimuli } \\
\text { - Female ASD individuals at CHR-P had more general and } \\
\text { positive symptoms on the SIPS } \\
\text { - The presence of formal thought disorder in ASD ranged } \\
\text { between } 16.5 \text { and } 60.4 \% \\
\text { - ASD at CHR-P showed more social anhedonia } \\
\text { - The frequency of ASD at CHR-P was reported as being } \\
1.1-39.6 \% \\
\text { - the occurrence of CHR-P in ASD oscillated between } 0 \text { to } \\
78.0 \% \\
\text { - Conversion rates of ASD at CHR-P range from } 15.4 \text { to } \\
18.2 \% \text { at } 2 \text { years of follow-up. ASD status was not associ- } \\
\text { ated with differential rates of conversion } \\
\text { - The most used psychopharmacological treatment were } \\
\text { antipsychotics }\end{array}$ & $\begin{array}{l}\text { - } 11.6 \%(95 \% \text { CI } 2.1-44.2) \text { of CHR-P individuals have an ASD } \\
\text { diagnosis } \\
\text { - Heterogeneity was significant, }\left(\mathrm{Q}=75.157, \mathrm{I}^{2}=96.008 \%\right) \\
\text { - Egger's test result }(0.425) \text { did not reveal significant publica- } \\
\text { tion bias, }(\mathrm{p}=0.712)\end{array}$ \\
\hline ASD vs CHR-P & $\begin{array}{l}\text { - The mean age was } 11.09 \text { years for ASD } \\
\text { - The mean age was } 18.23 \text { years for CHR-P } \\
\text { - Among those CHR-P individuals without ASD, } 91.3-100 \% \\
\text { 4.6-11.3\% met GRD criteria } \\
\text { - ASD individuals without CHR-P had less impairment on so } \\
\text { - ASD with psychotic-like symptoms and ASD without psych } \\
\text { patterns. Retrosplenial-temporal, cinguloparietal, and cingul } \\
\text { psychotic-like symptoms, ASD with psychotic-like sympton } \\
\text { - Conversion rate in CHR-P without ASD ranged } 11.1-14 \% \\
\text { - Antipsychotics (19.0-50.0\% versus } 25.0 \% \text { ) and psychostimu } \\
\text { quently in ASD than in CHR-P } \\
\text { - Anxiolytics }(11.3 \% \text { vs } 5.0 \%) \text { were prescribed more frequent }\end{array}$ & $\begin{array}{l}\text { net the APS criteria; } 0.8-11.3 \% \text { met BLIPS criteria and } \\
\text { ial cognition } \\
\text { tic-like symptoms are characterized by distinct connectivity } \\
\text { o-opercular connectivity most strongly predicted ASD without } \\
\text { s, and psychotic-like symptoms without ASD respectively } \\
2 \text { years } \\
\text { ants (15.6-48.0\% versus } 2.5 \% \text { ) were prescribed more fre- } \\
\text { y in CHR-P than in ASD }\end{array}$ \\
\hline
\end{tabular}

$A D H D$ attention deficit hyperactivity disorder, $A P S$ attenuated psychotic symptoms, $A S D$ autism spectrum disorder, $B L I P S$ brief limited intermittent psychotic symptoms, $B S$ basic symptoms, $C H R-P$ clinical high risk for psychosis, $G R D$ genetic risk and deterioration syndrome, $O D D$ oppositional defiant disorder, SIPS Structured Interview for Prodromal Syndromes

\section{Functioning, Cognition and Quality of Life}

Individuals with ASD at CHR-P showed: (i) a significantly greater impairment in structural and pragmatic language, and social functioning domains compared to subjects at CHR-P without ASD (Solomon et al., 2011); (ii) a considerably poorer global functioning than those ASD individuals without CHR-P (Foss-Feig et al., 2018, 2019; Sprong et al., 2008); and (iii) a poorer social cognition than ASD without CHR-P (Foss-Feig et al., 2018, 2019).

In terms of social functioning, CHR-P individuals with ASD had higher impairment in facial affect recognition (Maat et al., 2020) and showed slower responses for affective and non-affective face stimuli than those without ASD (Maat et al., 2020). 
With regard to cognitive functioning, the mean IQ in individuals with ASD ranged between 94.4 to 114.0 (Eussen et al., 2014; Foss-Feig et al., 2019; Maat et al., 2020; Solomon et al., 2008, 2011; Sprong et al., 2008; Wilson et al., 2020).

\section{Neuroimaging \& Neurophysiology}

Considering neural correlates between both conditions, one study reported on resting-state functional connectivity in youth with co-occurring ASD with prodromal psychosis symptoms, showing that the cingulo-parietal connectivity most strongly predicted ASD with psychotic-like symptoms (Jutla et al., 2020a, b). With regard to electrophysiological findings, ASD individuals at CHR-P showed a larger P300 wave amplitude in response to visual stimuli than CHR-P subjects without ASD (Foss-Feig et al., 2018; Guillory et al., 2018a, b).

\section{Clinical Characteristics, Prediction of Outcomes and Conversion}

In our systematic review, prodromal psychosis symptoms in ASD appeared in young people, (mean age range 8.82-18.53). Interestingly, although individuals with ASD and CHR-P were more frequently male, (ranging from 52.3 to $90.1 \%$ ), female ASD individuals at CHR-P were somewhat more impaired, obtaining higher scores on the SIPS Positive symptoms (Sprong et al., 2008), the SIPS-General symptoms (Sprong et al., 2008) and the BSABS-P Perceptual disturbances subscales (Sprong et al., 2008).

At baseline, positive psychotic symptoms were common in ASD. The occurrence of formal thought disorder in ASD ranged between 16.5 and 60.4\% (Eussen et al., 2014). Likewise, attenuated positive symptoms were common in ASD at follow-up: $37.5 \%$ had non-bizarre ideas (Eussen et al., 2014), 40.6\% unusual thought content (Eussen et al., 2014), and $43.7 \%$ displayed perceptual disturbances (Eussen et al., 2014).

Fig. 2 Meta-analysis: ASD in CHR-P. Forest plot
Considering the negative symptoms, ASD individuals at CHR-P showed more social anhedonia than those at CHR-P without ASD (Foss-Feig et al., 2019). Furthermore, schizotypal traits were more common in ASD and CHR-P than in the control group (Maat et al., 2020; Sprong et al., 2008). However, there were no differences regarding schizotypal traits between ASD and CHR-P (Maat et al., 2020; Sprong et al., 2008).

The presence of ASD in CHR-P ranged between 1.1 and 39.6\% (Foss-Feig et al., 2018, 2019; Fraser et al., 2008; Guillory et al., 2018a, b; Maat et al., 2020; Solomon et al., 2011). On the other hand, the occurrence of prodromal psychotic symptoms in ASD oscillated between 0 to $78.0 \%$ (Jutla et al., 2020a, b; Sprong et al., 2008; Wilson et al., 2020).

Four studies had data that allowed meta-analyses, comprising 875 individuals at CHR-P (Foss-Feig et al., 2019; Maat et al., 2020; Solomon et al., 2011; Sprong et al., 2008). According to our meta-analysis, $11.6 \%$ (95\% CI 2.1-44.2) of CHR-P individuals have an ASD diagnosis (Foss-Feig et al., 2019; Maat et al., 2020; Solomon et al., 2011; Sprong et al., 2008) (Fig. 2). Heterogeneity was significant, $(Q=75.157$, $\left.\mathrm{I}^{2}=96.008 \%\right)$. Additionally, Egger's test result (0.425) did not reveal significant publication bias $(\mathrm{p}=0.712)$ (eSupplementary Table 5; eSupplementary Fig. 1).

Conversion rates to psychosis of ASD individuals at CHR-P ranged from 15.4 to $18.2 \%$ at 2 years of follow-up (Foss-Feig et al., 2018, 2019; Guillory et al., 2018a, b), in comparison with conversion rates in CHR-P without ASD, which ranged $11.1-14.0 \%$ at 2 years (Foss-Feig et al., 2018, 2019; Guillory et al., 2018a, b). Further, formal thought disorder in ASD was associated with increased severity of ASD symptoms, but not with conversion to psychosis (Eussen et al., 2014) (eSupplementary Table 6).

\section{Interventions}

The use of psychotropics was more frequent in those with ASD than those with CHR-P, (62.5\% vs $45.0 \%$ respectively)

\begin{tabular}{lllllll} 
Study name & \multicolumn{5}{c}{ Statistics for each study } \\
\cline { 3 - 6 } & $\begin{array}{c}\text { Event } \\
\text { rate }\end{array}$ & $\begin{array}{c}\text { Lower } \\
\text { limit }\end{array}$ & $\begin{array}{c}\text { Upper } \\
\text { limit }\end{array}$ & Z-Value p-Value \\
Sprong2008 & 0,047 & 0,012 & 0,168 & $-4,171$ & 0,000 \\
Foss-Feig2019 & 0,034 & 0,023 & 0,050 & $-16,768$ & 0,000 \\
Solomon2011 & 0,200 & 0,066 & 0,470 & $-2,148$ & 0,032 \\
Maat2020 & 0,396 & 0,275 & 0,532 & $-1,500$ & 0,134 \\
& 0,116 & 0,021 & 0,442 & $-2,212$ & 0,027
\end{tabular}

Event rate and $95 \% \mathrm{CI}$

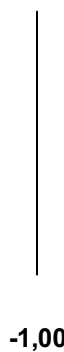

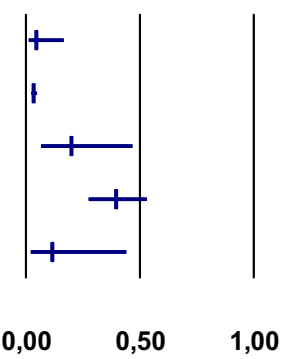


(Sprong et al., 2008), with a predominance of antipsychotic prescriptions (Sprong et al., 2008). Antipsychotics (19.0-50.0\% versus $25.0 \%)$ and psychostimulants (15.6-48.0\% versus $2.5 \%$ ) were prescribed more frequently in ASD than in CHR-P (Sprong et al., 2008; Wilson et al., 2020). Conversely, anxiolytics (11.3\% versus $5.0 \%)$ were prescribed more frequently in CHR-P than in ASD (Sprong et al., 2008; Wilson et al., 2020). Antidepressants were given in $12.5-38.0 \%$ individuals with ASD and in $22.5 \%$ in individuals at CHR-P (Sprong et al., 2008; Wilson et al., 2020). Response to treatment was not reported. There are no clinical trials in ASD at CHR-P.

\section{Quality Assessment}

The quality of the studies included was $5.31 \pm 1.85$ and ranged from 3 to 7 . The complete results are detailed in eSupplementary Tables 7 and 8.

\section{Discussion}

To our knowledge, this is the first systematic review and meta-analysis to comprehensively evaluated the evidence on the relationship between ASD and CHR-P.

We systematically reviewed 13 studies, focusing on both distinctive and overlapping features between both conditions. We further addressed meta-analytically the presence of ASD in individuals at CHR-P. Our overall sample included a total of 16,474 individuals, despite the fact that the majority of CHR-P studies specifically try to exclude ASD.

Although individuals with ASD with prodromal psychosis may represent a heterogeneous group, its baseline sociodemographic characteristics are now clearer. Typically, these individuals are young, (mean age range 8.82-18.53 years), males (53.5\%) who mostly present with APS (up to $100 \%$ ), and have associated impairments in global functioning, social functioning and social cognition.

Considering the different CHR-P groups, our review showed that up to $100 \%$ of ASD individuals at CHR-P fulfilled APS criteria (Foss-Feig et al., 2019; Maat et al., 2020; Solomon et al., 2011), 4.0\% met GRD criteria (Foss-Feig et al., 2019) and 3.1\% met criteria for BLIPS (Sprong et al., 2008). Likewise, $36.7 \%$ met criteria for Basic Symptoms (Sprong et al., 2008). Our review showed that the proportion fulfilling criteria for APS was somewhat higher (100\% vs $85 \%$ ) and lower for BLIPS (3.1\% vs $10 \%$ ) in ASD at CHR-P compared to that reported by Fusar-Poli et al. in CHR-P individuals (Fusar-Poli et al., 2020a, b). This difference may be because the majority of CHR-P studies exclude individuals with ASD.

Furthermore, at presentation, ASD individuals with prodromal psychosis symptoms often had other non-psychotic symptoms. The most commonly reported were ADHD symptoms, present in up to $52 \%$ in our review (Wilson et al., 2020), which is somewhat higher $(33.0-52.0 \%$ vs $28.0 \%$ ) compared to that reported in prior studies (Lai et al., 2019; Simonoff et al., 2008). Regarding ADHD symptoms, prior literature has reported that attenuated psychotic experiences in ASD are associated with the cooccurrence of attention problems (Gadow, 2012). The second most common was anxiety-related symptoms reported in up to $44 \%$ (Eussen et al., 2014), which is no different from that previously described in ASD subjects in some studies, informed in 41.9\% (Simonoff et al., 2008). However, this rate was higher than reported by other researchers, where the prevalence of anxiety in ASD was reported in $20.0 \%$ (Lai et al., 2019). In our review, the rate of anxiety is much higher compared to previous studies on CHR$\mathrm{P}$, where anxiety symptoms were present in $15.3 \%$ (FusarPoli et al., 2014a, b) and 21.3\% (Ribolsi et al., 2017) of individuals with attenuated psychosis syndrome. Additionally, $8.8 \%$ of individual with ASD with formal thought disorder met criteria for mood disorder (Eussen et al., 2014). This figure is no different from individuals with ASD without CHR-P, where depressive disorder is reported in $1.4 \%$ (Simonoff et al., 2008) to 12.9\%. (Leyfer et al., 2006). Nevertheless, this rate was much lower than that reported in previous studies in individuals at CHR-P (Fusar-Poli et al., 2014a, b). A recent meta-analysis reported that $40.7 \%$ of CHR-P population have comorbid depressive disorders (Fusar-Poli et al., 2014a, b). Individuals at CHR-P are characterized by a high prevalence of depressive and anxiety symptoms in addition to their attenuated psychotic symptoms (Fusar-Poli et al., 2014a, b). These symptoms might reflect essential emotional dysregulation processes and delusional mood in prodromal psychosis (Fusar-Poli et al., 2014a, b). In this line, there is some evidence that emotional disturbances in ASD may mediate psychotic experiences (Solomon et al., 2008). Specifically, formal thought disorder in ASD can be induced by anxiety (Solomon et al., 2008), and higher rates of psychotic experiences in ASD is associated with significant symptoms of anxiety and thought disorder (Sprong et al., 2008).

According to our results, social difficulties are present in ASD and CHR-P, which is in line with prior studies (Addington et al., 2017; Sugranyes et al., 2011b). We have highlighted that ASD individuals at CHR-P had more impaired social functioning (Foss-Feig et al., 2018, 2019; Sprong et al., 2008), and poorer social cognition (Foss-Feig et al., 2018, 2019) than ASD without prodromal psychosis. CHR-P individuals with ASD had higher impairment in facial affect recognition, and showed slower responses for affective and non-affective face stimuli (Maat et al., 2020). This is consistent with the earlier concept that facial recognition and processing in ASD is impaired (Tang et al., 2015). Further, 
it is undisputed that ASD (Black et al., 2017) and psychotic disorders (Savla et al., 2013) are characterized by deficits in facial emotion processing.

When cognition is considered, various hypotheses have been suggested to explain how neurological functions are altered in ASD and psychotic disorders (Baron-Cohen \& Belmonte, 2005; Brüne, 2004; Burns, 2004; Happé \& Frith, 2006). A point of consensus in these hypotheses is that cognitive dysfunctions are determined by altered interactions between and within components of the human social brain, including the amygdala, orbitofrontal cortex, anterior cingulate cortex, medial prefrontal cortex, and the mirror-neuron systems, among other neurological structures (Crespi \& Badcock, 2008).

Increased psychosis rates in individuals with ASD (Gadow, 2012; Konstantareas \& Hewitt, 2001; Selten et al., 2015); autistic traits leading to a higher risk of psychosis (Bevan Jones et al., 2012; Sullivan et al., 2013) molecular genetics findings (Burbach \& van der Zwaag, 2009; Guilmatre et al., 2009); neuroimaging findings (Eack et al., 2017; Foss-Feig et al., 2017), and deficits in social cognition (Pinkham et al., 2008; Sugranyes et al., 2011a, b) may indicate a common pathway between ASD and psychosis.

Several overlapping symptoms between ASD and CHR-P have been described. (Table 3). Taking into account cognitive models in computational neuroscience, ASD and psychotic symptoms might result from an imbalance between top-down and bottom-up perceptual processing (van Schalkwyk et al., 2017). From a cognitive neuroscience perspective, there are multiple areas of overlap between ASD and psychotic disorders, and this theoretical overlap might explain the overlapping symptomatology between both conditions (van Schalkwyk et al., 2017), especially in higherlevel predictions and social function, manifest as delusional beliefs (van Schalkwyk et al., 2017). Further, from a clinical perspective, psychotic symptoms appear to occur in ASD more frequently than may be expected (Dossetor, 2007; Van Schalkwyk et al., 2015). In this line, a retrospective study of 84 individuals with ASD found that $51 \%$ had psychotic symptoms (Kyriakopoulos et al., 2015), suggesting that psychosis might be particularly common in ASD. Additionally, a previous study showed that between 20 and $50 \%$ of people with childhood-onset schizophrenia had ASD (Rapoport et al., 2009). Further, ASD traits appear to be prevalent in 9.6-61.0\% of individuals with psychosis (Kincaid et al., 2017).

To refine detection and prognosis at the individual level, future research may contemplate specific risk factors (e.g., sex, trauma and living status), cognitive functioning (e.g., processing speed and verbal and visual memory) and biomarkers (e.g., neuroimaging data).

Considering neuroimaging findings, our review showed that ASD with psychotic-like symptoms and ASD without psychotic-like symptoms are characterized by distinct connectivity patterns (Jutla et al., 2020a, b), which is in line with prior studies from the literature, where stimulus-specific differences between both conditions have been reported (Sugranyes et al., 2011a, b).

Our findings suggest that individuals at CHR-P with ASD were younger than CHR-P without autism. The differentiating feature is that the symptoms in CHR-P are new-onset, usually during late adolescence, unlike ASD, which begins in early pre-school years. Furthermore, in most services and studies that include CHR-P population, the age of the individuals included typically ranges between 16 and 35 years (Fusar-Poli et al., 2013b, 2020b). Our findings also showed that ASD and CHR-P appear more frequently in males; nonetheless, female sex was associated with more general and positive symptoms on the SIPS in ASD individuals at CHR-P compared to males (Sprong et al., 2008). This is in line with evidence from a prior study on subclinical psychotic symptoms in the general population, which showed that females individuals had higher rates of positive psychotic experiences (Maric et al., 2003).

The findings also indicate that prodromal psychotic symptoms are common in ASD, with perceptual disturbances, unusual thought content and non-bizarre ideas being high (Eussen et al., 2014; Solomon et al., 2008). Further, 16.5\% displayed loose associations and $60.4 \%$ had illogical thinking (Eussen et al., 2014). Additionally, loose associations were related to autism communication deficits and anxiety (Solomon et al., 2008). When features of formal thought disorder are present in ASD, they are not necessarily comorbid psychotic disorder, but likely are evidence of symptomatic overlap with the pragmatic language abnormalities inherent in autism. The increase in the identification of these psychotic experiences in ASD may be due to the increased interest in early detection, and because the symptoms may appear in both conditions.

Our meta-analysis showed that $11.6 \%$ (95\% CI 2.1-44.2) of CHR-P individuals have an ASD diagnosis, which is in keeping with the results from the review. Our findings showed that the presence of ASD in CHR-P ranged between 1.1 and 39.6\% (Foss-Feig et al., 2018, 2019; Fraser et al., 2008; Guillory et al., 2018a, b; Maat et al., 2020; Solomon et al., 2011). Interestingly, the occurrence of CHR-P in ASD oscillated between 0 to $78.0 \%$ (Jutla et al., 2020a, b; Sprong et al., 2008; Wilson et al., 2020). This discrepancy may be due to the heterogeneity of the samples, with different sample sizes, as well as the use of different diagnostic measures to define CHR-P status. Additionally, a sample included individuals who did not meet strict criteria for autism but did fulfil the criteria for the Multiple Complex Developmental Disorder (MCDD), a distinct group within the autistic spectrum based on symptomatology (Cohen et al., 1986, 1994), with 
Table 3 Symptom overlap between ASD and CHR-P

\begin{tabular}{|c|c|c|c|}
\hline Symptoms & ASD & CHR-P & Comments \\
\hline Symptoms present before 3 years (early developmental period) & +++ & - & In ASD, symptoms typically appear during pre-school years \\
\hline Emergence of symptoms in adolescence or young adulthood & - & +++ & $\begin{array}{l}\text { Not seen in ASD. CHR-P usually appears in 12-35-year-olds } \\
\text { individuals }\end{array}$ \\
\hline Deficits in social-emotional reciprocity & +++ & + & Core ASD symptom. May appear in CHR-P \\
\hline Deficits in nonverbal communicative behaviours & +++ & + & Core ASD symptom. May appear in CHR-P \\
\hline $\begin{array}{l}\text { Deficits in developing, maintaining, and understanding rela- } \\
\text { tionships }\end{array}$ & +++ & + & Core ASD symptom. May appear in CHR-P \\
\hline $\begin{array}{l}\text { Stereotyped or repetitive motor movements, use of objects, or } \\
\text { speech }\end{array}$ & +++ & ++ & Core symptom in ASD. May appear in CHR-P \\
\hline $\begin{array}{l}\text { Insistence on sameness, inflexible adherence to routines, or } \\
\text { ritualised patterns of behaviour }\end{array}$ & +++ & + & $\begin{array}{l}\text { Core symptom in ASD. Rituals may occasionally appear in } \\
\text { CHR-P }\end{array}$ \\
\hline Highly restricted, fixated interests & +++ & + & Core symptom in ASD. Uncommon in CHR-P \\
\hline $\begin{array}{l}\text { Hyper or hypo-reactivity to sensory input or unusual interest } \\
\text { in sensory aspects of environment }\end{array}$ & +++ & - & Core symptom in ASD. Does not typically appear in CHR-P \\
\hline Unusual thought content & + & +++ & $\begin{array}{l}\text { Core symptom in CHR-P. May appear in ASD associated with a } \\
\text { circumscribed intense interest }\end{array}$ \\
\hline Thought interference & - & +++ & Core symptom in CHR-P. Not typical in ASD \\
\hline Thought perseveration & ++ & +++ & Core symptom in CHR-P. May appear in ASD \\
\hline Thought pressure & - & ++ & Frequent in CHR-P. Not typical in ASD \\
\hline Thought blockages & - & ++ & Frequent in CHR-P. Not typical in ASD \\
\hline Suspiciousness & + & +++ & $\begin{array}{l}\text { Core symptom in CHR-P. May appear in ASD, particularly in } \\
\text { those who misconstrue social cues }\end{array}$ \\
\hline Unstable ideas of reference & - & +++ & Frequent in CHR-P. Not typical in ASD \\
\hline Perceptual abnormalities & + & +++ & $\begin{array}{l}\text { Core symptom in CHR-P. May appear in ASD as part of 'imagi- } \\
\text { nary friends' since early life and not a new phenomenon }\end{array}$ \\
\hline Visual perception disturbances & + & ++ & $\begin{array}{l}\text { Core symptom in CHR-P. May appear in ASD due to sensory } \\
\text { issues }\end{array}$ \\
\hline Acoustic perception disturbances & + & +++ & $\begin{array}{l}\text { Core symptom in CHR-P. May appear in ASD due to sensory } \\
\text { hyperresponsivity but is not a new-onset phenomenon }\end{array}$ \\
\hline $\begin{array}{l}\text { Decreased ability to discriminate between ideas, perception, } \\
\text { fantasy and true memories }\end{array}$ & + & ++ & Frequent in CHR-P. May appear in ASD \\
\hline Derealisation & - & ++ & Frequent in CHR-P. Not typical in ASD \\
\hline Disorganised communication & + & +++ & Core symptom in CHR-P. May appear in ASD \\
\hline Disturbance of expressive speech & ++ & ++ & Core symptom in CHR-P. May appear in ASD \\
\hline Disturbance of receptive speech & +++ & +++ & Core symptom in CHR-P and ASD \\
\hline Grandiose ideas & - & +++ & Core symptom in CHR-P. Not typically present in ASD \\
\hline Disturbances of abstract thinking & +++ & ++ & Core symptom in ASD. May appear in CHR-P \\
\hline Inability to divide attention & ++ & ++ & May appear in ASD and CHR-P \\
\hline Captivation of attention by details of the visual field & +++ & ++ & Core symptom in ASD. May appear in CHR-P \\
\hline Mannerism & +++ & + & Core symptom in ASD. May appear in CHR-P \\
\hline Stereotypy & +++ & + & Core symptom in ASD. May appear in CHR-P \\
\hline Agitation not influenced by external stimuli & ++ & ++ & Frequently reported in ASD and CHR-P \\
\hline
\end{tabular}

$A S D$ autism spectrum disorder, $C H R-P$ clinical high risk for psychosis

more psychotic features, constituting a population at risk, with greater vulnerability to develop psychosis (Jansen et al., 2000). Furthermore, MCDD is characterized by early childhood-onset emotional dysregulation with high levels of anxiety, aggressiveness and thought disorder, with a remarkably elevated risk of psychosis (Cohen et al.,
1994; Van Engeland \& Van der Gaag, 1994) (eSupplementary Table 9).

Further, we also found that conversion rates of ASD individuals at CHR-P ranged from 15.4 to $18.2 \%$ at 2 years of follow-up, which was not different from CHR-P without ASD, (11.1-14.0\% at 2 years) (Eussen et al., 2014; 
Foss-Feig et al., 2018, 2019; Guillory et al., 2018a, b). ASD status was not associated with differential rates of conversion in comparison with CHR-P individuals without ASD. Besides, our rate was slightly lower than reported by other researchers in CHR-P population, where the transition risk was $20 \%$ at 2 years (Salazar De Pablo et al., 2020), 22-23\% at 3 years (Fusar-Poli et al., 2020a; Salazar De Pablo et al., 2020), and $19.6 \%$ at 6 years of follow-up (Ziermans et al., 2014).

Psychopharmacological treatment, especially antipsychotics, are used more frequently in subjects with ASD than in CHR-P (Sprong et al., 2008). In our review, the proportion of ASD treated with antipsychotics was somewhat higher, (19.0-50.0\% vs $7.0-34.0 \%$ ), compared to prior studies (Coury et al., 2012; Downs et al., 2016; Eussen et al., 2014; Murray et al., 2014) The increased use of antipsychotics may be related to its use in the treatment of behavioural symptoms in ASD (Alfageh et al., 2019; Owen et al., 2009; Shea et al., 2004). Moreover, a recent meta-analysis showed that there is little evidence to favour the use of antipsychotics to improve attenuated psychotic symptoms in CHR-P (Davies et al., 2018). Likewise, according to a previous meta-analysis, there is no evidence to support the superior efficacy of any intervention over another to reduce attenuated positive psychotic symptoms.

\section{Limitations}

Limitations include the small number of studies evaluated and the heterogeneity of diagnostic criteria used in these studies. Firstly, most of the studies on CHR-P specifically exclude patients with ASD, therefore we have fewer studies to include into this analysis. Also, due to the lack of sufficient data on both CHR-P and ASD in publications, we could only use four studies in our meta-analysis to evaluate the presence of ASD in CHR-P. Secondly, no gold-standard measures have been used to define ASD in these studies. Likewise, there is no gold-standard measure to define CHR-P status. Nevertheless, the four studies included in the metanalysis defined CHR-P state using the Structured Interview for Prodromal Syndromes (SIPS), which is a validated measure to describe CHR-P (Fusar-Poli et al., 2016). Thirdly, due to the lack of data in publications, we were not able to meta-analyse the presence of CHR-P in ASD. And fourth, the scarce available data did not allow us to do meta-regression analyses to examine the relationship of characteristics such as clinical, psychopathological, therapeutic, cognitive and neurobiological aspects within both conditions. Nevertheless, the total number of participants included in the current metanalysis is sizeable and the results are significant with precise $95 \%$ CIs.
Longitudinal studies are required to address the overlap between ASD and CHR-P. Special consideration may need to be given to how to assess prodromal psychotic experiences in individuals with ASD. Lifelong symptoms with pre-school onset should be differentiated from recent-onset symptoms. Symptom ratings for CHR-P should ensure that only symptoms that are of recent onset are used during CHR-P evaluation to avoid diagnostic overshadowing. Longitudinal studies that measure anxiety, low mood, stressful life events and treatment response in CHR-P, with and without ASD, will further our understanding.

\section{Conclusion}

Features of prodromal psychosis are present in individuals with ASD. They are more common in males, but females may display more severe symptoms. There is evidence of psychopathological overlap between both conditions, which may hinder the diagnostic process and treatment. Individuals with ASD at CHR-P have significantly poorer global functioning and poorer social cognition than ASD without CHRP. There are no differences in comorbidity in ASD with or without CHR-P. The presence of ASD is not associated with conversion to psychosis. Prompt detection, assessment, and intervention in this population have the potential to maximise the benefits of early interventions.

Supplementary Information The online version contains supplementary material available at https://doi.org/10.1007/s10803-021-05046-0.

Acknowledgments Dr Julio Vaquerizo-Serrano and Gonzalo Salazar de Pablo are supported by the Alicia Koplowitz Foundation.

Author Contributions ICMJE statement: all authors meet all four ICMJE criteria for authorship and have approved the final version of this manuscript. Dr JV-S had full access to all of the data in the study and takes responsibility for the integrity of the data and the accuracy of the data analysis. Study concept and design: PS. Acquisition, analysis, or interpretation of data: JV-S, GSdP Statistical analysis: JV-S, GSdP. Drafting of the manuscript: JV-S, PS. Study supervision: PS, JS. Critical revision of the manuscript for important intellectual content: PS, JS, JV-S, GSdP.

\section{Declarations}

Conflict of interest The authors declare that they have no conflict of interests.

Open Access This article is licensed under a Creative Commons Attribution 4.0 International License, which permits use, sharing, adaptation, distribution and reproduction in any medium or format, as long as you give appropriate credit to the original author(s) and the source, provide a link to the Creative Commons licence, and indicate if changes 
were made. The images or other third party material in this article are included in the article's Creative Commons licence, unless indicated otherwise in a credit line to the material. If material is not included in the article's Creative Commons licence and your intended use is not permitted by statutory regulation or exceeds the permitted use, you will need to obtain permission directly from the copyright holder. To view a copy of this licence, visit http://creativecommons.org/licenses/by/4.0/.

\section{References}

Abu-Akel, A., \& Bailey, A. L. (2000). The possibility of different forms of theory of mind impairment in psychiatric and developmental disorders. Psychological Medicine, 30, 735-738. https://doi.org/ 10.1017/S0033291799002123

Abu-Akel, A. M., Wood, S. J., Hansen, P. C., \& Apperly, I. A. (2015). Perspective-taking abilities in the balance between autism tendencies and psychosis proneness. Proceedings of the Royal Society B: Biological Sciences, 282(1808), 1-8. https://doi.org/10. 1098/rspb.2015.0563

Adams, R. A., Stephan, K. E., Brown, H. R., Frith, C. D., \& Friston, K. J. (2013). The computational anatomy of psychosis. Frontiers in Psychiatry, 4(May), 1-26. https://doi.org/10.3389/fpsyt.2013. 00047

Addington, J., Liu, L., Perkins, D. O., Carrion, R. E., Keefe, R. S. E., $\&$ Woods, S. W. (2017). The role of cognition and social functioning as predictors in the transition to psychosis for youth with attenuated psychotic symptoms. Schizophrenia Bulletin. https:// doi.org/10.1093/schbul/sbw152

Aleman, A., Böcker, K. B. E., Hijman, R., De Haan, E. H. F., \& Kahn, R. S. (2003). Cognitive basis of hallucinations in schizophrenia: Role of top-down information processing. Schizophrenia Research. https://doi.org/10.1016/S0920-9964(03)00060-4

Aleman, A., \& Kahn, R. S. (2005). Strange feelings: Do amygdala abnormalities dysregulate the emotional brain in schizophrenia? Progress in Neurobiology. https://doi.org/10.1016/j.pneurobio. 2005.11.005

Alfageh, B. H., Wang, Z., Mongkhon, P., Besag, F. M. C., Alhawassi, T. M., Brauer, R., \& Wong, I. C. K. (2019). Safety and tolerability of antipsychotic medication in individuals with autism spectrum disorder: A systematic review and meta-analysis. Pediatric Drugs. https://doi.org/10.1007/s40272-019-00333-x

American Psychiatric Association. (1987). DSM-III-R: Diagnostic and Statistical Manual of Mental Disorders. revised. American Psychiatric Association.

American Psychiatric Association. (2013). Diagnostic and statistical manual of mental disorders (5th ed.). American Journal of Psychiatry. https://doi.org/10.1176/appi.books.9780890425596. 744053

Badcock, C. (2004). Mentalism and mechanism: The twin modes of human cognition. Evolutionary Psychology, Public Policy and Personal Decisions. https://doi.org/10.4324/9781410609892

Badcock, C., \& Crespi, B. (2006). Imbalanced genomic imprinting in brain development: An evolutionary basis for the aetiology of autism. Journal of Evolutionary Biology. https://doi.org/10. 1111/j.1420-9101.2006.01091.x

Baron-Cohen, S., \& Belmonte, M. K. (2005). Autism: A window onto the development of the social and the analytic brain. Annual Review of Neuroscience. https://doi.org/10.1146/annurev.neuro. 27.070203.144137

Bevan Jones, R., Thapar, A., Lewis, G., \& Zammit, S. (2012). The association between early autistic traits and psychotic experiences in adolescence. Schizophrenia Research. https://doi.org/10.1016/j. schres.2011.11.037

Bishop-Fitzpatrick, L., Mazefsky, C. A., Eack, S. M., \& Minshew, N. J. (2017). Correlates of social functioning in autism spectrum disorder: The role of social cognition. Research in Autism Spectrum Disorder, 35, 25-34. https://doi.org/10.1016/j.rasd.2016.11.01

Black, M. H., Chen, N. T. M., Iyer, K. K., Lipp, O. V., Bölte, S., Falkmer, M., Tan, T., \& Girdler, S. (2017). Mechanisms of facial emotion recognition in autism spectrum disorders: Insights from eye tracking and electroencephalography. Neuroscience and Biobehavioral Reviews. https://doi.org/10.1016/j.neubiorev. 2017.06.016

Bleuler, E. (1911). Dementia Praecox: Or the group of schizophrenias. International Universities Press.

Borenstein, M., Hedges, L., Higgins, J., \& Rothstein, H. (2005). Software comprehensive meta-analysis (version 2). Biostat.

Broks, P. (1997). Brain, self, and others: The neuropsychology of social cognition. Schizotypy: Implications for Illness and Health, ed. G. Claridge, 98-123.

Brüne, M. (2004). Schizophrenia—An evolutionary enigma? Neuroscience and Biobehavioral Reviews. https://doi.org/10.1016/j.neubi orev.2003.10.002

Burbach, J. P. H., \& van der Zwaag, B. (2009). Contact in the genetics of autism and schizophrenia. Trends in Neurosciences. https:// doi.org/10.1016/j.tins.2008.11.002

Burns, J. K. (2004). An evolutionary theory of schizophrenia: Cortical connectivity, metarepresentation, and the social brain. Behavioral and Brain Sciences. https://doi.org/10.1017/S0140525X0 4000196

Burns, J. (2006). The social brain hypothesis of schizophrenia. Psychiatria Danubina, 5(2), 77

Cheung, C., Yu, K., Fung, G., Leung, M., Wong, C., Li, Q., Sham, P., Chua, S., \& McAlonan, G. (2010). Autistic disorders and schizophrenia: Related or remote? An anatomical likelihood estimation. PLOS ONE. https://doi.org/10.1371/journal.pone.0012233

Chisholm, K., Lin, A., Abu-Akel, A., \& Wood, S. J. (2015). The association between autism and schizophrenia spectrum disorders: A review of eight alternate models of co-occurrence. Neuroscience and Biobehavioral Reviews. https://doi.org/10.1016/j.neubiorev. 2015.04.012

Cohen, D. J., Paul, R., \& Volkmar, F. R. (1986). Issues in the classification of pervasive and other developmental disorders: Toward DSM-IV. Journal of the American Academy of Child Psychiatry. https://doi.org/10.1016/S0002-7138(09)60228-4

Cohen, D. J., Towbin, K. E., Mayes, L., \& Volkmar, F. (1994). Developmental psychopathology of multiplex developmental disorder. In H. H. Carl, \& S. L. Friedman (Eds.), Developmental followup: Concepts, genres, domains, and methods. Academic Press.

Courchesne, E., Pierce, K., Schumann, C. M., Redcay, E., Buckwalter, J. A., Kennedy, D. P., \& Morgan, J. (2007). Mapping early brain development in autism. Neuron, 56(2), 399-413. https://doi.org/ 10.1016/j.neuron.2007.10.016

Coury, D. L., Anagnostou, E., Manning-Courtney, P., Reynolds, A., Cole, L., McCoy, R., Whitaker, A., \& Perrin, J. M. (2012). Use of psychotropic medication in children and adolescents with autism spectrum disorders. Pediatrics. https://doi.org/10.1542/ peds.2012-0900D

Crespi, B., \& Badcock, C. (2008). Psychosis and autism as diametrical disorders of the social brain. Behavioral and Brain Sciences. https://doi.org/10.1017/S0140525X08004214

Davidson, C., Greenwood, N., Stansfield, A., \& Wright, S. (2014). Prevalence of Asperger syndrome among patients of an early intervention in psychosis team. Early Intervention in Psychiatry. https://doi.org/10.1111/eip.12039 
Davies, C., Radua, J., Cipriani, A., Stahl, D., Provenzani, U., McGuire, P., \& Fusar-Poli, P. (2018). Efficacy and acceptability of interventions for attenuated positive psychotic symptoms in individuals at clinical high risk of psychosis: A network meta-analysis. Frontiers in Psychiatry. https://doi.org/10.3389/fpsyt.2018.00187

De Crescenzo, F., Postorino, V., Siracusano, M., Riccioni, A., Armando, M., Curatolo, P., \& Mazzone, L. (2019). Autistic symptoms in schizophrenia spectrum disorders: A systematic review and meta-analysis. Frontiers in Psychiatry. https://doi. org/10.3389/fpsyt.2019.00078

DerSimonian, R., \& Laird, N. (1986). Meta-analysis in clinical trials. Controlled Clinical Trials, 7(3), 177-188

Dossetor, D. R. (2007). 'All that glitters is not gold': Misdiagnosis of psychosis in pervasive developmental disorders-A case series. Clinical Child Psychology and Psychiatry, 12(4), 537-548. https://doi.org/10.1177/1359104507078476

Downs, J., Hotopf, M., Ford, T., Simonoff, E., Jackson, R. G., Shetty, H., Stewart, R., \& Hayes, R. D. (2016). Clinical predictors of antipsychotic use in children and adolescents with autism spectrum disorders: A historical open cohort study using electronic health records. European Child and Adolescent Psychiatry. https://doi.org/10.1007/s00787-015-0780-7

Eack, S. M., Wojtalik, J. A., Keshavan, M. S., \& Minshew, N. J. (2017). Social-cognitive brain function and connectivity during visual perspective-taking in autism and schizophrenia. Schizophrenia Research. https://doi.org/10.1016/j.schres.2017.03.009

Egger, M., Smith, G. D., Schneider, M., \& Minder, C. (1997). Bias in meta-analysis detected by a simple, graphical test. British Medical Journal. https://doi.org/10.1136/bmj.316.7129.469

Emery, N. J. (2000). The eyes have it: The neuroethology, function and evolution of social gaze. Neuroscience and Biobehavioral Reviews. https://doi.org/10.1016/S0149-7634(00)00025-7

Eussen, M. L. J. M., de Bruin, E. I., Van Gool, A. R., Louwerse, A., van der Ende, J., Verheij, F., Verhulst, F. C., \& GreavesLord, K. (2014). Formal thought disorder in autism spectrum disorder predicts future symptom severity, but not psychosis prodrome. European Child and Adolescent Psychiatry. https:// doi.org/10.1007/s00787-014-0552-9

Foss-Feig, J. H., Adkinson, B. D., Ji, J. L., Yang, G., Srihari, V. H., McPartland, J. C., Krystal, J. H., Murray, J. D., \& Anticevic, A. (2017). Searching for cross-diagnostic convergence: Neural mechanisms governing excitation and inhibition balance in schizophrenia and autism spectrum disorders. Biological Psychiatry. https://doi.org/10.1016/j.biopsych.2017.03.005

Foss-Feig, J., Velthorst, E., Guillory, S., Hamilton, H., Roach, B., Bachman, P., Belger, A., Carrion, R., Duncan, E., Johannesen, J., Light, G., Margaret Niznikiewicz, M., Addington, J., Cadenhead, K., Cannon, T., Cornblatt, B., McGlashan, T., Perkins, D., Seidman, L., ... Mathalon, D. (2018). Architecture of psychosis symptoms and neural predictors of conversion among clinical high risk individuals with autism spectrum disorder. Schizophrenia Bulletin. https://doi.org/10.1093/schbul/sby017. 649

Foss-Feig, J. H., Velthorst, E., Smith, L., Reichenberg, A., Addington, J., Cadenhead, K. S., Cornblatt, B. A., Mathalon, D. H., McGlashan, T. H., Perkins, D. O., Seidman, L. J., Stone, W. S., Keshavan, M., Tsuang, M. T., Walker, E. F., Woods, S. W., Cannon, T. D., \& Bearden, C. E. (2019). Clinical profiles and conversion rates among young individuals with autism spectrum disorder who present to clinical high risk for psychosis services. Journal of the American Academy of Child and Adolescent Psychiatry. https://doi.org/10.1016/j.jaac.2018.09.446

Fraser, R., Thompson, A., Allott, K., Luxmoore, M., Woodhead, G., \& Cotton, S. (2008). Prevalence of autism spectrum disorders in ultra high risk for psychosis and first episode psychosis cohorts. Early Intervention in Psychiatry, 2, A44-A44
Fusar-Poli, P., Borgwardt, S., Bechdolf, A., Addington, J., RiecherRössler, A., Schultze-Lutter, F., Keshavan, M., Wood, S., Ruhrmann, S., Seidman, L. J., Valmaggia, L., Cannon, T., Velthorst, E., De Haan, L., Cornblatt, B., Bonoldi, I., Birchwood, M., McGlashan, T., Carpenter, W., ... Yung, A. (2013a). The psychosis high-risk state: A comprehensive state-of-the-art review. Archives of General Psychiatry. https://doi.org/10.1001/jamap sychiatry.2013.269

Fusar-Poli, P., Byrne, M., Badger, S., Valmaggia, L. R., \& McGuire, P. K. (2013b). Outreach and support in South London (OASIS), 2001-2011: Ten years of early diagnosis and treatment for young individuals at high clinical risk for psychosis. European Psychiatry. https://doi.org/10.1016/j.eurpsy.2012.08.002

Fusar-Poli, P., Cappucciati, M., Rutigliano, G., Lee, T. Y., Beverly, Q., Bonoldi, I., Lelli, J., Kaar, S. J., Gago, E., Rocchetti, M., Patel, R., Bhavsar, V., Tognin, S., Badger, S., Calem, M., Lim, K., Kwon, J. S., Perez, J., \& McGuire, P. (2016). Towards a standard psychometric diagnostic interview for subjects at ultra high risk of psychosis: CAARMS versus SIPS. Psychiatry Journal. https:// doi.org/10.1155/2016/7146341

Fusar-Poli, P., Carpenter, W. T., Woods, S. W., \& McGlashan, T. H. (2014a). Attenuated Psychosis Syndrome: Ready for DSM-5.1? Annual Review of Clinical Psychology. https://doi.org/10.1146/ annurev-clinpsy-032813-153645

Fusar-Poli, P., Nelson, B., Valmaggia, L., Yung, A. R., \& McGuire, P. K. (2014b). Comorbid depressive and anxiety disorders in 509 individuals with an at-risk mental state: Impact on psychopathology and transition to psychosis. Schizophrenia Bulletin. https:// doi.org/10.1093/schbul/sbs136

Fusar-Poli, P., Rocchetti, M., Sardella, A., Avila, A., Brandizzi, M., Caverzasi, E., Politi, P., Ruhrmann, S., \& McGuire, P. (2015). Disorder, not just state of risk: Meta-analysis of functioning and quality of life in people at high risk of psychosis. British Journal of Psychiatry. https://doi.org/10.1192/bjp.bp.114.157115

Fusar-Poli, P., Salazar De Pablo, G., Correll, C. U., Meyer-Lindenberg, A., Millan, M. J., Borgwardt, S., Galderisi, S., Bechdolf, A., Pfennig, A., Kessing, L. V., van Amelsvoort, T., Nieman, D. H., Domschke, K., Krebs, M. O., Koutsouleris, N., McGuire, P., Do, K. Q., \& Arango, C. (2020a). Prevention of psychosis: Advances in detection, prognosis, and intervention. JAMA Psychiatry. https://doi.org/10.1001/jamapsychiatry.2019.4779

Fusar-Poli, P., Spencer, T., De Micheli, A., Curzi, V., Nandha, S., \& McGuire, P. (2020b). Outreach and support in South-London (OASIS) 2001-2020: Twenty years of early detection, prognosis and preventive care for young people at risk of psychosis. European Neuropsychopharmacology. https://doi.org/10.1016/j.euron euro.2020.08.002

Gadow, K. D. (2012). Schizophrenia spectrum and attention-deficit/ hyperactivity disorder symptoms in autism spectrum disorder and controls. Journal of the American Academy of Child and Adolescent Psychiatry, 51(10), 1076-1084. https://doi.org/10. 1016/j.jaac.2012.08.001

Geuze, E., Vermetten, E., \& Bremner, J. D. (2005). MR-based in vivo hippocampal volumetrics: 2. Findings in neuropsychiatric disorders. Molecular Psychiatry. https://doi.org/10.1038/sj.mp. 4001579

Gilmore, J. H., Kang, C., Evans, D. D., Wolfe, H. M., Smith, M. D., et al. (2010). Prenatal and neonatal brain structure and white matter maturation in children at high risk for schizophrenia. American Journal of Psychiatry, 167(9), 1083-1091. https://doi.org/ 10.1176/appi.ajp.2010.09101492

Gisabella, B., Bolshakov, V. Y., \& Benes, F. M. (2005). Regulation of synaptic plasticity in a schizophrenia model. Proceedings of the National Academy of Sciences of the United States of America. https://doi.org/10.1073/pnas.0506034102 
Grossberg, S., \& Seidman, D. (2006). Neural dynamics of autistic behaviors: Cognitive, emotional, and timing substrates. Psychological Review. https://doi.org/10.1037/0033-295X.113.3.483

Guillory, S., Velthorst, E., Hamilton, H., Roach, B., Bachman, P., Belger, A., Carrion, R., Duncan, E., Johannesen, J., Light, G., Niznikiewicz, M., \& Mathalon, D. (2018a). Atypical P300 amplitude differentiates conversion patterns in psychosis prodrome when autism spectrum disorder is comorbid. Biological Psychiatry, 83(9), S317-S318

Guillory, S., Velthorst, E., Hamilton, H., Roach, B., Bachman, P., Belger, A., Carrion, R., Duncan, E., Johannesen, J., Niznikiewicz, M., Cadenhead, K., Foss-Feig, J., \& Mathalon, D. (2018b). Atypical P300, but not MMN, amplitude differentiates conversion patterns in psychosis prodrome with versus without comorbid autism spectrum disorder. Early Intervention in Psychiatry. https://doi.org/10.1111/eip.12722

Guilmatre, A., Dubourg, C., Mosca, A. L., Legallic, S., Goldenberg, A., Drouin-Garraud, V., Layet, V., Rosier, A., Briault, S., BonnetBrilhault, F., Laumonnier, F., \& Campion, D. (2009). Recurrent rearrangements in synaptic and neurodevelopmental genes and shared biologic pathways in schizophrenia, autism, and mental retardation. Archives of General Psychiatry. https://doi.org/10. 1001/archgenpsychiatry.2009.80

Gur, R. E., Keshavan, M. S., \& Lawrie, S. M. (2007). Deconstructing psychosis with human brain imaging. Schizophrenia Bulletin. https://doi.org/10.1093/schbul/sbm045

Hamlyn, J., Duhig, M., McGrath, J., \& Scott, J. (2013). Modifiable risk factors for schizophrenia and autism-Shared risk factors impacting on brain development. Neurobiology of Disease, 53, 3-9

Happé, F., \& Frith, U. (2006). The weak coherence account: Detailfocused cognitive style in autism spectrum disorders. Journal of Autism and Developmental Disorders. https://doi.org/10.1007/ s10803-005-0039-0

Harrington, L., Langdon, R., Siegert, R. J., \& McClure, J. (2005a). Schizophrenia, theory of mind, and persecutory delusions. Cognitive Neuropsychiatry. https://doi.org/10.1080/1354680034 4000327

Harrington, L., Siegert, R. J., \& McClure, J. (2005b). Theory of mind in schizophrenia: A critical review. Cognitive Neuropsychiatry, 10(4), 249-286. https://doi.org/10.1080/13546800444000056

Hoffman, R. E., Woods, S. W., Hawkins, K. A., Pittman, B., Tohen, M., Preda, A., Breier, A., Glist, J., Addington, J., Perkins, D. O., \& McGlashan, T. H. (2007). Extracting spurious messages from noise and risk of schizophrenia-spectrum disorders in a prodromal population. British Journal of Psychiatry. https://doi.org/10. 1192/bjp.bp.106.031195

Hommer, R. E., \& Swedo, S. E. (2015). Schizophrenia and autismRelated disorders. Schizophrenia Bulletin. https://doi.org/10. 1093/schbul/sbu 188

Horga, G., Schatz, K. C., Abi-Dargham, A., \& Peterson, B. S. (2014). Deficits in predictive coding underlie hallucinations in schizophrenia. Journal of Neuroscience, 34(24), 8072-8082. https:// doi.org/10.1523/JNEUROSCI.0200-14.2014

Hugdahl, K. (2009). 'hearing voices': Auditory hallucinations as failure of top-down control of bottom-up perceptual processes. Scandinavian Journal of Psychology. https://doi.org/10.1111/j.14679450.2009.00775.x

Iglesias, S., Tomiello, S., Schneebeli, M., \& Stephan, K. E. (2017). Models of neuromodulation for computational psychiatry. Wiley Interdisciplinary Reviews: Cognitive Science, 8(3), 1-22. https:// doi.org/10.1002/wcs. 1420

Jansen, L. M. C., Gispen-de Wied, C. C., Van der Gaag, R. J., ten Hove, F., Willemsen-Swinkels, S. W. M., Harteveld, E., \& Van Engeland, H. (2000). Unresponsiveness to psychosocial stress in a subgroup of autistic-like children, Multiple Complex
Developmental Disorder. Psychoneuroendocrinology. https://doi. org/10.1016/S0306-4530(00)00020-2

Jüni, P., Witschi, A., Bloch, R., \& Egger, M. (1999). The hazards of scoring the quality of clinical trials for meta-analysis. Journal of the American Medical Association. https://doi.org/10.1001/ jama.282.11.1054

Jutla, A., Donohue, M. R., Veenstra-Vanderweele, J., \& Foss-Feig, J. (2020a). Resting-state functional connectivity in youth with co-occurring autism spectrum disorder and psychotic-like symptoms. Biological Psychiatry. https://doi.org/10.1016/j.biopsych. 2020.02.322

Jutla, A., Donohue, M. R., Veenstra-VanderWeele, J., \& Foss-Feig, J. (2020b). Reported autism diagnosis strongly predicts psychoticlike experiences in the Adolescent Brain Cognitive Development cohort. medRxiv. https://doi.org/10.1101/2020.02.07.20021170

Kanner, L. (1943). Autistic disturbances of affective contact. Nervous child. Nervous Child. https://doi.org/10.1111/fwb.12896

Kanner, L. (1965). Infantile autism and the schizophrenias. Behavioral Science. https://doi.org/10.1002/bs.3830100404

Kincaid, D. L., Doris, M., Shannon, C., \& Mulholland, C. (2017). What is the prevalence of autism spectrum disorderand ASD traits in psychosis? A systematic review. Psychiatry Research, 250, 99-105.

Kolvin, I. (1971). Studies in the childhood psychoses. I. Diagnostic criteria and classification. The British Journal of Psychiatry: The Journal of Mental Science. https://doi.org/10.1192/bjp.118. 545.381

Konstantareas, M. M., \& Hewitt, T. (2001). Autistic disorder and schizophrenia: Diagnostic overlaps. Journal of Autism and Developmental Disorders. https://doi.org/10.1023/A:1005605528309

Kuroki, N., Kubicki, M., Nestor, P. G., Salisbury, D. F., Park, H. J., Levitt, J. J., Woolston, S., Frumin, M., Niznikiewicz, M., Westin, C. F., \& Shenton, M. E. (2006). Fornix integrity and hippocampal volume in male schizophrenic patients. Biological Psychiatry. https://doi.org/10.1016/j.biopsych.2005.09.021

Kushima, I., Aleksic, B., Nakatochi, M., Shimamura, T., Okada, T., Uno, Y., Morikawa, M., Ishizuka, K., Shiino, T., Kimura, H., Arioka, Y., Yoshimi, A., Takasaki, Y., Yu, Y., Nakamura, Y., Yamamoto, M., Iidaka, T., Iritani, S., Inada, T., ... Ozaki, N. (2018). Comparative analyses of copy-number variation in autism spectrum disorder and schizophrenia reveal etiological overlap and biological insights. Cell Reports. https://doi.org/10. 1016/j.celrep.2018.08.022

Kyriakopoulos, M., Stringaris, A., Manolesou, S., Radobuljac, M. D., Jacobs, B., Reichenberg, A., Stahl, D., Simonoff, E., Stahl, D., Simonoff, E., \& Frangou, S. (2015). Determination of psychosisrelated clinical profiles in children with autism spectrum disorders using latent class analysis. European Child and Adolescent Psychiatry. https://doi.org/10.1007/s00787-014-0576-1

Lai, M. C., Kassee, C., Besney, R., Bonato, S., Hull, L., Mandy, W., Szatmari, P., \& Ameis, S. H. (2019). Prevalence of co-occurring mental health diagnoses in the autism population: A systematic review and meta-analysis. The Lancet Psychiatry. https://doi.org/ 10.1016/S2215-0366(19)30289-5

Lavoie, M. A., Plana, I., Bédard Lacroix, J., Godmaire-Duhaime, F., Jackson, P. L., \& Achim, A. M. (2013). Social cognition in firstdegree relatives of people with schizophrenia: A meta-analysis. Psychiatry Research. https://doi.org/10.1016/j.psychres.2012. 11.037

Lee, T. Y., Hong, S. B., Shin, N. Y., \& Kwon, J. S. (2015). Social cognitive functioning in prodromal psychosis: A meta-analysis. Schizophrenia Research. https://doi.org/10.1016/j.schres.2015. 02.008

Leyfer, O. T., Folstein, S. E., Bacalman, S., Davis, N. O., Dinh, E., Morgan, J., Tager-Flusberg, H., \& Lainhart, J. E. (2006). Comorbid psychiatric disorders in children with autism: Interview 
development and rates of disorders. Journal of Autism and Developmental Disorders. https://doi.org/10.1007/s10803-006-0123-0

Lipsey, M. W., \& Wilson, D. B. (2001). Practical meta-analysis. Applied Social Research Methods Series. https://doi.org/10. 1016/j.autneu.2007.06.087

Maat, A., Therman, S., Swaab, H., \& Ziermans, T. (2020). The attenuated psychosis syndrome and facial affect processing in adolescents with and without autism. Frontiers in Psychiatry. https:// doi.org/10.3389/fpsyt.2020.00759

Maric, N., Krabbendam, L., Vollebergh, W., De Graaf, R., \& Van Os, J. (2003). Sex differences in symptoms of psychosis in a nonselected, general population sample. Schizophrenia Research. https://doi.org/10.1016/S0920-9964(02)00380-8

McGlashan, T., Walsh, B., \& Woods, S. (2010). (2019). The psychosisrisk syndrome: Handbook for diagnosis and follow-up. (O. U. Press., Ed.). Oxford University.

McGorry, P. D., \& Singh, B. S. (1995). Schizophrenia: Risk and possibility. Handbook of Studies on PreventivePsychiatry, B Raphael, GD Burrows, 491-514.

Murray, M. L., Hsia, Y., Glaser, K., Simonoff, E., Murphy, D. G. M., Asherson, P. J., Eklund, H., \& Wong, I. C. K. (2014). Pharmacological treatments prescribed to people with autism spectrum disorder (ASD) in primary health care. Psychopharmacology. https://doi.org/10.1007/s00213-013-3140-7

Ornitz, E. M., \& Ritvo, E. R. (1968). Perceptual inconstancy in early infantile autism: The syndrome of early infant autism and its variants including certain cases of childhood schizophrenia. Archives of General Psychiatry. https://doi.org/10.1001/archp syc.1968.01740010078010

Owen, R., Sikich, L., Marcus, R. N., Corey-Lisle, P., Manos, G., McQuade, R. D., Carson, W. H., \& Findling, R. L. (2009). Aripiprazole in the treatment of irritability in children and adolescents with autistic disorder. Pediatrics. https://doi.org/ 10.1542/peds.2008-3782

Page, M. J., McKenzie, J. E., Bossuyt, P. M., Boutron, I., Hoffmann, T. C., Mulrow, C. D., Shamseer L, Tetzlaff, J. M., Akl, E. A., Brennan, S. E., Chou, R., Glanville, J., Grimshaw, J. M., Hróbjartsson, A., Lalu, M. M., Li, T., Loder, E. W., MayoWilson, E., McDonald, S., ... Moher, D. (2021). The PRISMA 2020 statement: An updated guideline for reporting systematic reviews. Systematic Reviews, 10(1), 1-11. https://doi.org/10. 1186/s13643-021-01626-4

Palmer, C. J., Paton, B., Kirkovski, M., Enticott, P. G., \& Hohwy, J. (2015). Context sensitivity in action decreases along the autism spectrum: A predictive processing perspective. Proceedings of the Royal Society B: Biological Sciences, 282(1802), 1-9. https://doi.org/10.1098/rspb.2014.1557

Pinkham, A. E., Hopfinger, J. B., Pelphrey, K. A., Piven, J., \& Penn, D. L. (2008). Neural bases for impaired social cognition in schizophrenia and autism spectrum disorders. Schizophrenia Research. https://doi.org/10.1016/j.schres.2007.10.024

Pourcain, B. S., Robinson, E. B., Anttila, V., Sullivan, B. B., Maller, J., Golding, J., Skuse, D., Ring, S., Evans, D. M., Zammit, S., Fisher, S. E., \& Davey Smith, G. (2018). ASD and schizophrenia show distinct developmental profiles in common genetic overlap with population-based social communication difficulties. Molecular Psychiatry. https://doi.org/10.1038/mp.2016.198

Rapoport, J., Chavez, A., Greenstein, D., Addington, A., \& Gogtay, N. (2009). Autism spectrum disorders and childhood-onset schizophrenia: clinical and biological contributions to a relation revisited. Journal of the AmericanAcademy of Child \& Adolescent Psychiatry, 48(1), 10-18.

Ribolsi, M., Lin, A., Wardenaar, K. J., Pontillo, M., Mazzone, L., Vicari, S., \& Armando, M. (2017). Clinical presentation of Attenuated Psychosis Syndrome in children and adolescents:
Is there an age effect? Psychiatry Research. https://doi.org/10. 1016/j.psychres.2017.02.050

Rosello, B., Berenguer, C., Baixauli, I., García, R., \& Miranda, A. (2020). Theory of mind profiles in children with autism spectrum disorder: Adaptive/social skills and pragmatic competence. Frontiers in Psychology, 11(September), 1-14. https://doi.org/10. 3389/fpsyg.2020.567401

Salazar De Pablo, G., Catalan, A., \& Fusar-Poli, P. (2020). Clinical validity of DSM-5 attenuated psychosis syndrome: Advances in diagnosis, prognosis, and treatment. JAMA Psychiatry. https:// doi.org/10.1001/jamapsychiatry.2019.3561

Sampson, K. N., Upthegrove, R., Abu-Akel, A., Haque, S., Wood, S. J., \& Reniers, R. (2020). Co-occurrence of autistic and psychotic traits: Implications for depression, self-harm and suicidality. Psychological Medicine. https://doi.org/10.1017/S00332917200001 24

Savla, G. N., Vella, L., Armstrong, C. C., Penn, D. L., \& Twamley, E. W. (2013). Deficits in domains of social cognition in schizophrenia: A meta-analysis of the empirical evidence. Schizophrenia Bulletin. https://doi.org/10.1093/schbul/sbs080

Schultze-Lutter, F., Schimmelmann, B. G., \& Ruhrmann, S. (2011). The near Babylonian speech confusion in early detection of psychosis. Schizophrenia Bulletin. https://doi.org/10.1093/schbul/ sbr039

Schultze-Lutter, F., \& Theodoridou, A. (2017). The concept of basic symptoms: Its scientific and clinical relevance. World Psychiatry. https://doi.org/10.1002/wps.20404

Schultze-Lutter, F., Ruhrmann, S., Fusar-Poli, P., Bechdolf, A., Schimmelmann, G. B., \& Klosterkotter, J. (2012). Basic symptoms and the prediction of first-episode psychosis. Current Pharmaceutical Design. https://doi.org/10.2174/138161212799316064

Schumann, C. M., Hamstra, J., Goodlin-Jones, B. L., Lotspeich, L. J., Kwon, H., Buonocore, M. H., Lammers, C. R., Reiss, A. L., \& Amaral, D. G. (2004). The amygdala is enlarged in children but not adolescents with autism; the hippocampus is enlarged at all ages. Journal of Neuroscience. https://doi.org/10.1523/JNEUR OSCI.1297-04.2004

Selten, J. P., Lundberg, M., Rai, D., \& Magnusson, C. (2015). Risks for nonaffective psychotic disorder and bipolar disorder in young people with autism spectrum disorder: A population-based study. JAMA Psychiatry. https://doi.org/10.1001/jamapsychiatry.2014. 3059

Shea, S., Turgay, A., Carroll, A., Schulz, M., Orlik, H., Smith, I., \& Dunbar, F. (2004). Risperidone in the treatment of disruptive behavioral symptoms in children with autistic and other pervasive developmental disorders. Pediatrics. https://doi.org/10.1542/ peds.2003-0264-F

Simonoff, E., Pickles, A., Charman, T., Chandler, S., Loucas, T., \& Baird, G. (2008). Psychiatric disorders in children with autism spectrum disorders: Prevalence, comorbidity, and associated factors in a population-derived sample. Journal of the American Academy of Child and Adolescent Psychiatry. https://doi.org/10. 1097/CHI.0b013e318179964f

Solomon, M., Olsen, E., Niendam, T., Ragland, J. D., Yoon, J., Minzenberg, M., \& Carter, C. S. (2011). From lumping to splitting and back again: Atypical social and language development in individuals with clinical-high-risk for psychosis, first episode schizophrenia, and autism spectrum disorders. Schizophrenia Research. https://doi.org/10.1016/j.schres.2011.03.005

Solomon, M., Ozonoff, S., Carter, C., \& Caplan, R. (2008). Formal thought disorder and the autism spectrum: Relationship with symptoms, executive control, and anxiety. Journal of Autism and Developmental Disorders. https://doi.org/10.1007/ s10803-007-0526-6

Sprong, M., Becker, H. E., Schothorst, P. F., Swaab, H., Ziermans, T. B., Dingemans, P. M., Linszen, D., \& van Engeland, H. (2008). 
Pathways to psychosis: A comparison of the pervasive developmental disorder subtype Multiple Complex Developmental Disorder and the 'At Risk Mental State.' Schizophrenia Research. https://doi.org/10.1016/j.schres.2007.10.031

Sterne, J. A. C., Egger, M., \& Smith, G. D. (2001). Systematic reviews in health care: Investigating and dealing with publication and other biases in meta-analysis. British Medical Journal. https:// doi.org/10.1136/bmj.323.7304.101

Stroup, D. F., Berlin, J. A., Morton, S. C., Olkin, I., Williamson, G. D., Rennie, D., Moher, D., Becker, B. J., Sipe, T. A., \& Thacker, S. B. (2000). Meta-analysis of observational studies in epidemiology: A proposal for reporting. Journal of the American Medical Association. https://doi.org/10.1001/jama.283.15.2008

Sugranyes, G., Kyriakopoulos, M., Corrigall, R., \& Taylor, E. (2011a). Autism spectrum disorders and schizophrenia: An activation likelihood estimation meta-analysis of emotional face processing. European Child and Adolescent Psychiatry. https://doi.org/ 10.1007/s00787-011-0181-5

Sugranyes, G., Kyriakopoulos, M., Corrigall, R., Taylor, E., \& Frangou, S. (2011b). Autism spectrum disorders and schizophrenia: Metaanalysis of the neural correlates of social cognition. PLOS ONE. https://doi.org/10.1371/journal.pone.0025322

Sullivan, S., Rai, D., Golding, J., Zammit, S., \& Steer, C. (2013). The association between autism spectrum disorder and psychotic experiences in the Avon Longitudinal Study of Parents and Children (ALSPAC) birth cohort. Journal of the American Academy of Child and Adolescent Psychiatry. https://doi.org/10.1016/j. jaac.2013.05.010

Tang, J., Falkmer, M., Horlin, C., Tan, T., Vaz, S., \& Falkmer, T. (2015). Face recognition and visual search strategies in autism spectrum disorders: Amending and extending a recent review by Weigelt et al. PLOS ONE. https://doi.org/10.1371/journal.pone. 0134439

Toal, F., Bloemen, O. J., Deeley, Q., Tunstall, N., Daly, E. M., \& Page, L. (2009). Psychosis and autism: Magnetic resonance imaging study of brain anatomy. British Journal of Psychiatry. https://doi. org/10.1192/bjp.bp.107.049007

Van de Cruys, S., Evers, K., Hallen, V. D., Van Eylen, L., Boets, B., \& Wagemans, J. (2014). Precise minds in uncertain worlds: Predictive coding in autism. Psychological Review, 121(4), 649-675. https://doi.org/10.1037/a0037665
Van Engeland, H., \& Van der Gaag, R. (1994). MCDD in childhood: A precursor of schizophrenic spectrum disorders. Schizophrenia Research, 11, 197-197

Van Schalkwyk, G. I., Peluso, F., Qayyum, Z., McPartland, J. C., \& Volkmar, F. R. (2015). Varieties of misdiagnosis in ASD: An illustrative case series. Journal of Autism and Developmental Disorders, 45(4), 911-918. https://doi.org/10.1007/ s10803-014-2239-y

van Schalkwyk, G. I., Volkmar, F. R., \& Corlett, P. R. (2017). A predictive coding account of psychotic symptoms in autism spectrum disorder. Journal of Autism and Developmental Disorders, 47(5), 1323-1340. https://doi.org/10.1007/s10803-017-3065-9

Vladusich, T. (2008). Towards a computational neuroscience of autismpsychosis spectrum disorders. Behavioral and Brain Sciences. https://doi.org/10.1017/S0140525X08004433

Wilson, C. S., Anthony, L., Kenworthy, L., Fleischman, R., Demro, C., Andorko, N., Chelsea Armour, A., \& Schiffman, J. (2020). Feasibility of psychosis risk assessment for adolescents diagnosed with autism. Autism. https://doi.org/10.1177/1362361320909173

Yung, A. R., McGorry, P. D., McFarlane, C. A., Jackson, H. J., Patton, G. C., \& Rakkar, A. (1996). Monitoring and care of young people at incipient risk of psychosis. Schizophrenia Bulletin. https://doi. org/10.1093/schbul/22.2.283

Zheng, Z., Zheng, P., \& Zou, X. (2018). Association between schizophrenia and autism spectrum disorder: A systematic review and meta-analysis. Autism Research. https://doi.org/10.1002/aur.1977

Ziermans, T., De Wit, S., Schothorst, P., Sprong, M., Van Engeland, H., Kahn, R., \& Durston, S. (2014). Neurocognitive and clinical predictors of long-term outcome in adolescents at ultra-high risk for psychosis: A 6-year follow-up. PLOS ONE. https://doi.org/10. 1371/journal.pone.0093994

Ziermans, T. B., Schirmbeck, F., Oosterwijk, F., Geurts, H. M., \& De Haan, L. (2020). Autistic traits in psychotic disorders: Prevalence, familial risk, and impact on social functioning. Psychological Medicine. https://doi.org/10.1017/S0033291720000458

Publisher's Note Springer Nature remains neutral with regard to jurisdictional claims in published maps and institutional affiliations. 